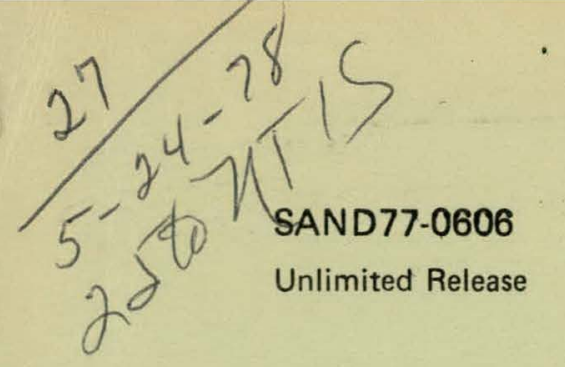

\title{
Equations of Motion for Free-Flight Systems of Rotating-Translating Bodies Having Variable Mass and Configuration
}

Albert E. Hodapp, Jr.

Prepared by Sandia Laboratories, Albuquerque, New Mexico 87185

and Livermore, California 94550 for the United States Department

of Energy under Contract AT(29-1)-789

Printed March 1978

\section{Sandia Laboratories}




\section{DISCLAIMER}

This report was prepared as an account of work sponsored by an agency of the United States Government. Neither the United States Government nor any agency Thereof, nor any of their employees, makes any warranty, express or implied, or assumes any legal liability or responsibility for the accuracy, completeness, or usefulness of any information, apparatus, product, or process disclosed, or represents that its use would not infringe privately owned rights. Reference herein to any specific commercial product, process, or service by trade name, trademark, manufacturer, or otherwise does not necessarily constitute or imply its endorsement, recommendation, or favoring by the United States Government or any agency thereof. The views and opinions of authors expressed herein do not necessarily state or reflect those of the United States Government or any agency thereof. 


\section{DISCLAIMER}

Portions of this document may be illegible in electronic image products. Images are produced from the best available original document. 
Issued by Sandia Laboratories, operated for the United States Department of Energy by Sandia Corporation.

\section{NOTICE}

This report was prepared as an account of work sponsored by the United States Government. Neither the United States nor the Department of Energy, nor any of their employees, nor any of their contractors, subcontractors, or their employees, makes any warranty, express or implied, or assumes any legal liability or responsibility for the accuracy, completeness or usefulness of any information, apparatus, product or process disclosed, or represents that its use would not infringe privately owned rights.

Printed in the United States of America

Available from

National Technical Information Service

U. S. Department of Commerce

5285 Port Royal Road

Springfield, VA 22161

Price: Printed Copy $\$ 4.50$; Microfiche $\$ 3.00$ 
SAND77-0606

Unlimited Release.

Printed March 1978

\title{
EQUIATIONS OF MOTION FOR FREE-FLIGHT SYSTEMS OF ROTATING-TRANSLATING BODIES \\ HAVING VARIABLE MASS AND CONFIGURATION
}

Albert E. Hodapp, Jr.

Aeroballistics Division 1331

Sandia Laboratories

Albuquerque, NM $\cdot 87185$

\begin{abstract}
General vector differential equations of motion are developed for a system of rotating-translating, unbalanced, variable mass, variable configuration bodies. Complete flexibility is provided. in placement of the reference coordinates within the system of bodies and in placement of body fixed axes within each body. Dxamples are presented to demonatratc the easc with which these equations can be reduced to the equations of motion for systems of interest.
\end{abstract}

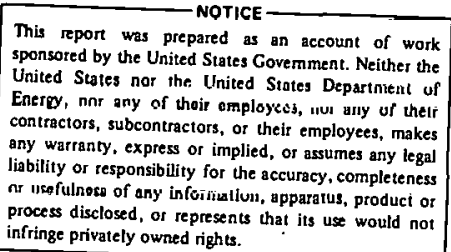


The author wishes to thank S. E. Benzley (1282) and J. K. Cole (1336) for their thorough review of the variable mass equations, and J. M. Alcone (5742) for his helpful consultation. 


\section{CONTENTS}

Nomenclature

Introduction and Summary

Theoretical Analysis

Particle Dynamics

jth Body Dynamics

System Dynamics

Example Cases

Rotating Internal Mass

Morriblo Joint

Conclusion

References

\section{ILLUSTRATIONS}

Figure

1 Coordinate Systems and Particle Locations

2 Particle Mass Variation

3 Spinning - Thrusting Body With Rotating Internal Component

4 Spinning-Thrusting Body With Flexible Joint 


\section{Nomenclature}

$$
\begin{aligned}
& \text { cg Center of gravity } \\
& \frac{\mathrm{d}(\mathrm{)}}{\mathrm{dt}} \quad \text { Derivative of ( ) with respect to time } \\
& \text { F Total force (external + gravitational) acting on the system of bodies } \\
& {\left[\sum_{j} F_{j}, E q .(73)\right] \text {, lb or } N} \\
& \mathrm{~F}_{\mathbf{j}} \quad \text { Total force (external + gravitational + interaction) acting on the } \mathrm{j} \underline{\mathrm{th}} \\
& \text { body }\left[\sum_{p} F_{j p}+T_{j} \text {, Eq. (39) }\right] \text {, lb or } N \\
& F_{j p} \\
& F_{X}, F_{Y}, F_{Z} \\
& g_{X}, g_{Y}, g_{Z} \\
& \mathrm{H}_{\mathrm{j}} \\
& i, j, k \\
& i_{j}, j_{j}, k_{j} \\
& I_{X_{j}}, I_{Y_{j}} ; I_{Z_{j}} \\
& I_{X_{j} Y_{j}}, I_{Y_{j} Z_{j}} \cdot I_{X_{j} Z_{j}} \\
& \mathrm{~m} \\
& m_{. j} \\
& \mathrm{~m}_{\mathrm{jp}} \\
& M_{o}, M_{j_{o}}, M_{j p_{o}} \\
& M_{X}, M_{Y}, M_{Z} \\
& \mathrm{M}_{\mathrm{X}_{2}}, \mathrm{M}_{\mathrm{Y}_{2}} ; \mathrm{M}_{\mathrm{Z}_{2}}
\end{aligned}
$$




\begin{tabular}{|c|c|c|}
\hline$P_{j p}$ & & $\begin{array}{l}\text { Linear momentum of the variable mass particle "p" (Figure 1) of } \\
\text { the } j \text { th body }[\mathrm{Eq} .(5)], 1 b-s \text { or } \mathrm{N}-\mathrm{s}\end{array}$ \\
\hline$r_{c g}$ & . & $\begin{array}{l}\text { Radius vector from "o" (origin of } \mathrm{XYZ} \text { axes) to the } \mathrm{cg} \text { of the system } \\
\text { of bodies, Figure } 1 \text { [Eq. (72)], ft or } \mathrm{m}\end{array}$ \\
\hline $\mathrm{r}_{\mathrm{j}}$ & & $\begin{array}{l}\text { Radius vector from "o" (origin of } X Y Z \text { axes) to the origin of the } \\
X_{j} Y_{j} Z_{j} \text { axes, Figure 1, ft or } m\end{array}$ \\
\hline $\mathbf{R}_{\mathrm{o}}$ & & $\begin{array}{l}\text { Radius vector from origin of } X_{i} Y_{i} Z_{i} \text { axes to "o" (origin of } X Y Z \text { axes), } \\
\text { Figure } 1 \text {, ft or } \mathrm{m}\end{array}$ \\
\hline $\mathrm{t}$ & & Time, s \\
\hline $\mathbf{T}_{j}$ & & Total thrust acting on $j$ th body [Eq. (36), external force], lb or $\mathrm{N}$ \\
\hline $1 u_{j}$ & & $\begin{array}{l}\text { Velnrity of ejerted ar swallowed mass (volosity of " } q \text { ", Figuro } 1 \text { ) } \\
\text { relative to the reference point at the exit from or entrance to the } j \text { th } \\
\text { body }[E q .(20)], \int l / s \text { or } \mathrm{m} / \mathrm{s}\end{array}$ \\
\hline $\mathrm{V}$ & & $\begin{array}{l}\text { Velocity of "o" (origin of } X Y Z \text { axes, Figure 1) relative to inertial } \\
\text { space, } \mathrm{ft} / \mathrm{s} \text { or } \mathrm{m} / \mathrm{s}\end{array}$ \\
\hline $\mathrm{XYZ}$ & & $\begin{array}{l}\text { Reference coordinates for system of bodies (arbitrary location and } \\
\text { motion), Figure } 1\end{array}$ \\
\hline$X_{i} Y_{i} Z_{i}$ & & Inertially fixed coordinates, Figure 1 \\
\hline$X_{j} Y_{j} Z_{j}$ & . & Coordinates fixed in the $j \underline{\text { th }}$ body (arbitrary location in body), Figure 1 \\
\hline$\Delta()$ & & Difference or change in ( ) \\
\hline$\rho_{\text {icg }}$ & & $\begin{array}{l}\text { Radius vector from origin of } X_{j} Y_{j} Z_{j} \text { axes to the } c g \text { of the } j \text { th body } \\
{[\text { Eq. (16)], Figure 1, ft or } m}\end{array}$ \\
\hline & & $\begin{array}{l}\text { Radius vector from origin of } X_{j} Y_{j} Z_{j} \text { axes to the point in the } j \text { th body } \\
\text { either at the center of the nozzle exit plane or inlet entrance plane, } \\
\text { Figure } 1, \mathrm{ft} \text { or } \mathrm{m}\end{array}$ \\
\hline$\rho_{\mathrm{jm}}$ & & $\begin{array}{l}\text { Radius vector from origin of } X_{j} Y_{j} Z_{j} \text { axes to the } c g \text { (point " } c^{\prime \prime} \text { ) of the } \\
\text { mass slug incuming to or outgoing from the } j \text { th body, Figure } 1 \text {, ft or } m\end{array}$ \\
\hline & & $\begin{array}{l}\text { Radius vector from origin of } X_{j} Y_{j} Z_{j} \text { axes to the particle " } p \text { " of the } j \underline{\text { th }} \\
\text { body, Figurc } 1 \text {, ft or } m\end{array}$ \\
\hline$\rho_{\mathrm{jpm}}$ & & $\begin{array}{l}\text { Radius vector from " } p \text { " to the mass particle incoming to or outgoing } \\
\text { from " } p \text { ", Figure } 1 \mathrm{ft} \text { or } \mathrm{m}\end{array}$ \\
\hline$\rho_{\mathrm{jp} \Delta \mathrm{m}}$ & & Radius vector from " $c$ " to a particle of the mass slug, Figure 1, ft or $\mathrm{m}$ \\
\hline$\sum_{\mathrm{p}}, \sum_{\mathrm{j}}$ & & $\begin{array}{l}\text { Summations for all particles " } p \text { " of the } j \text { th body and for all } j \text { bodies of } \\
\text { the system, respectively }\end{array}$ \\
\hline
\end{tabular}


$\psi, \theta$

$\omega_{\mathrm{j}}$

$\Omega$

$(-),(\rightarrow),\left({ }^{n}\right)$

\{\}

$(\cdot j) \cdot(\cdot \cdot)$
Yaw, pitch sequence of angular rotations respectively, to define the position of $\mathrm{X}_{2} \mathrm{Y}_{2} \mathrm{Z}_{2}$ relative to $\mathrm{X}_{1} \mathrm{Y}_{1} \mathrm{Z}_{1}$ (i. e. , Body 2 relative to Body 1 , Figure 4), rad or deg

Angular velocity of the $\mathrm{j}$ th body relative to inertial space, radis

Angular velocity of the reference $X Y Z$ axes relative to inertial space, rad/s

Denotes vectors resolved relative to the $X_{i} Y_{i} Z_{i}, X Y Z$, and $X_{j} Y_{j} Z_{j}$

axes, respectively

Vector, column matrix

First and second derivatives with respect to time 


\section{EQUATIONS OF MOTION FOR FREE-FLIGHT SYSTEMS OF ROTATING-TRANSLATING BODIES \\ HAVING VARIABLE MASS AND CONFIGURATION}

Introduction and Summary

Often when dealing with the flight dynamics and control problems associated with missiles, reentry vehicles, aircraft, spacerraft, bombs, and shells the need arises for describing the motion of systems of varying-mass, varying-configuration bodies. Examples of systems of this type are thrusting missiles, thrusting aircraft, inflatable structures, etc., having moving control surfaces and/or moving internal components: Because of the large number of possible variations in the configurations of multiple body systems, it is desirable to have a general set of equations that can be easily reduced to describe dynamic systems of interest. For the aeroballistician it is particularly desirable to have a general set of equations that can easily implement the use of a non rolling reference coordinate frame. Equations of motion for multiple body systems can be found in the literature; however, they are usually derived for rigid bodies (no mass or configuration variation) and do not provide for easy implementation of nonrolling reference coordinates; e.g. , Reference 1. Unfortunately, even for single bodies, many incomplete general derivations of the variable mass equations appear in the literature; e.g., the incomplete force and moment equations of References 2 and 3.

Beginning with the development of variable mass particle dynamics, vector differential equations are derived herein that provide a complete description for the motion of a system of rotatingtranslating, variable-mass, variable configuration, bodies. With respect to placement of coordinate frames, these general equations of motion, like the earlier rigid body equations derived by the author, 4 are different from previous derivations in that the reference coordinate frame for the system is not required to be fixed in any of the bodies. The angular velocities of the individual bodies and the angular velocity of the reference coordinate frame can all differ. In addition, the coordinate frame in each body of the system is not required to have its origin fixed at the body cg. This flexibility in placement of the reference coordinate frame and each of the body fixed coordinate frames can be of great advantage in simplifying the equations for specific applications. For example; the requirement for nonrolling reference axes is easily implemented, as is the simulation of unbalanced bodies.

By introducing restraints (e.g.. limiting the number of bodies, limiting their degrees of freedom, defining the dynamic coupling of the bodies, etc.), the general equations presented herein can be reduced in form to describe the equations of motion for many multiple body or single body dynamic systems of interest. These systems can contaln rigid bodies as well as bodies of varying 
mass and/or configuration. To demonstrate the flexibility and usefulness of these equations, two simplified cases are considered. For the first, equations of motion are developed relative to nonrolling coordinates for a spinning-thrusting body containing an internal rotating mass. The second example involves the development of equations of motion to describe the effects of a flexible joint on the dynamics of a spinning-thrusting combination of bodies. Examples for rigid body systems are presented in Reference 4. These include equations of motion relative to nonrolling coordinates for a spinning body having mass asymmetries, and equations of motion for a spinning body having an internal flexible vibrating member. The equations resulting from these examples are useful for describing the free-flight motions of both aerodynamically stabilized and gyroscopically stabilized spinning vehicles.

'Theoretical Analysis

In Figure 1, the positions of the $j$ bodies $(j=1,2, \ldots, n)$, which make up the system of interest, are described relative to both inertial space $\left(X_{i} Y_{i} Z_{i}\right)$ and the reference coordinate system (XYZ). The center of mass or center of gravity $(\mathrm{cg})$ for the system of bodies is not required to be coincident with the origin " $O$ " of the reference coordinates. These bodies translate and rotate relative to one another as well as relative to the rotating reference frame XYZ. The body fixed coordinate system $X_{j} Y_{j} Z_{j}$ can be located arbitrarily in the $j$ th body; therefore, as shown in Figure 1 , the bodies can have $\mathrm{cg}$ offsets.

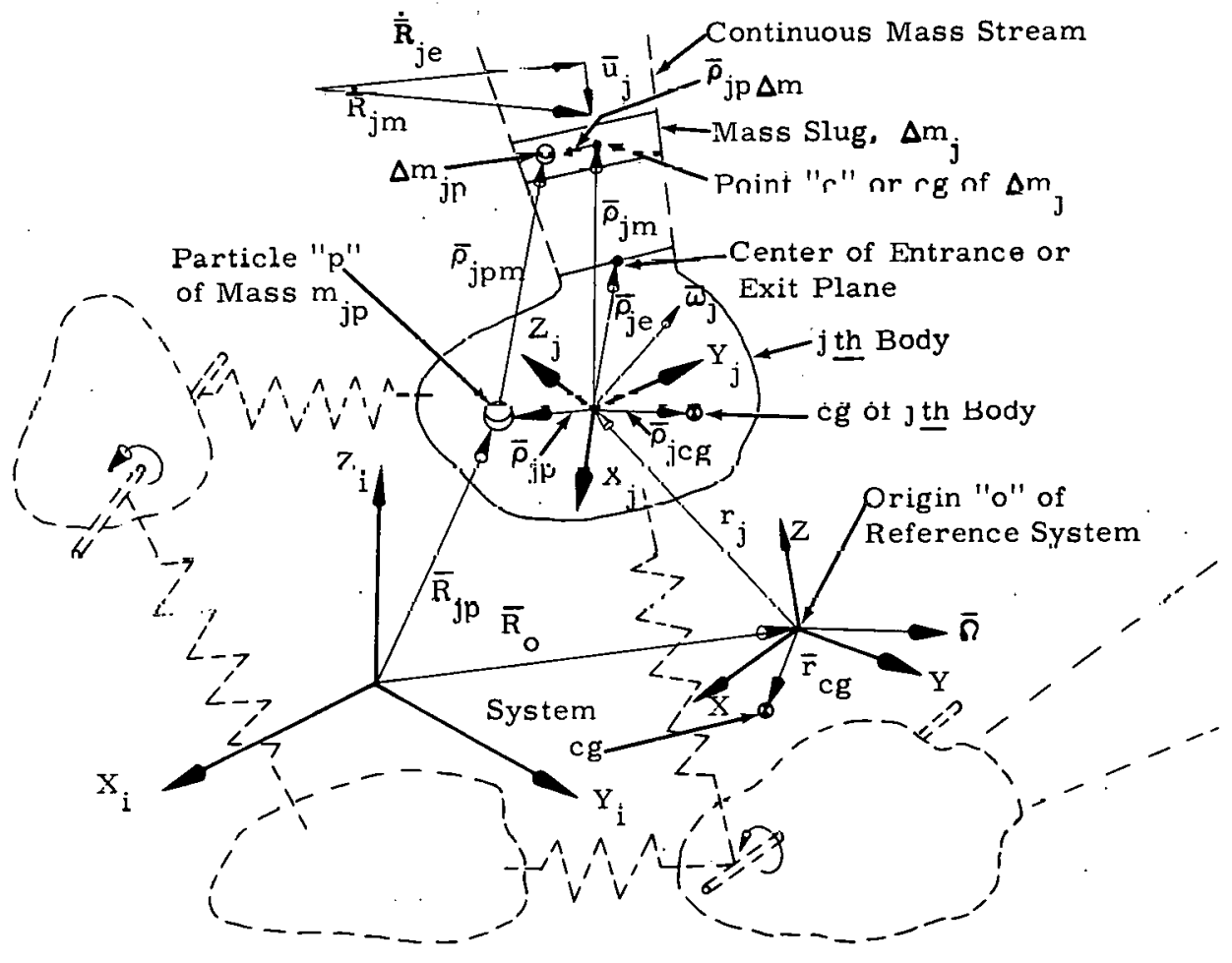

Figure 1. Coordinate Systems and Particle Locations 
For the following development, the symbol above a vector quantity denotes the coordinate frame in which the vector is resolved and also the çoordinate frame in which derivatives of the vector are taken. Examples are $\bar{r}_{j}$ and $\dot{\bar{r}}_{j}, \vec{r}_{j}$ and $\vec{r}_{j}$, or $\dot{r}_{j}$ and $\dot{\vec{r}}_{j}$. These respective groups indicate vectors resolved relative to, and derivatives taken with respect to, the $X_{i} Y_{i} Z_{i}$ inertial coordinates, the $X Y Z$ reference coordinates, and the $X_{j} Y_{j} Z_{j}$ body-fixed coordinates.

\section{Particle Dynamics}

As shown in Figure 1, the radius vectors $\bar{R}_{j p}$, from the origin of the $X_{i} Y_{i} Z_{i}$ inertial refer-: ence system to the particle " $p$ " of the $j$ th body; and $\bar{R}_{j p m}$, from the origin of the $X_{i} Y_{i} Z_{i}$ system to the mass particle incoming to or outgoing from " $p$ ", are described by

$$
\begin{aligned}
& \overline{\mathbf{R}}_{j p}=\overline{\mathbf{R}}_{o}+\overline{\mathbf{r}}_{j}+\bar{\rho}_{j p} \\
& \overline{\mathbf{R}}_{j p m}=\overline{\mathbf{R}}_{o}+\overline{\mathbf{r}}_{j}+\bar{\rho}_{j m}+\bar{\rho}_{j p \Delta m}=\bar{R}_{j p}+\bar{\rho}_{j p m} .
\end{aligned}
$$

The force acting on the variable mass particle " $p$ ". and the moment of that force about the origin "o" of the reference XYZ coordinate frame are given as

$$
\begin{aligned}
& \bar{F}_{j p}=\frac{d}{d t}\left(\bar{P}_{j p}\right) \\
& \bar{M}_{j p_{o}}=\left(\bar{r}_{j}+\bar{\rho}_{j p}\right) \times \bar{F}_{j p}
\end{aligned}
$$

where the instantaneous linear momentum of the particle " $p$ " is given as

$$
\overline{\mathrm{P}}_{j p}=\mathrm{m}_{\mathrm{jp}} \dot{\overline{\mathrm{R}}}_{\mathrm{jp}}
$$

Equation (3) is intended to apply only to a system of definite mass. As indicated by Greenwonn, ${ }^{1}$ Thomson. ${ }^{2}$ Meriam, ${ }^{5}$ and others, the equation can be applied to a system of varying mass provided the same mass is examined for the change in momentum at two instances of time. The example used to depict this (Figure 2) is of a particle gaining mass.
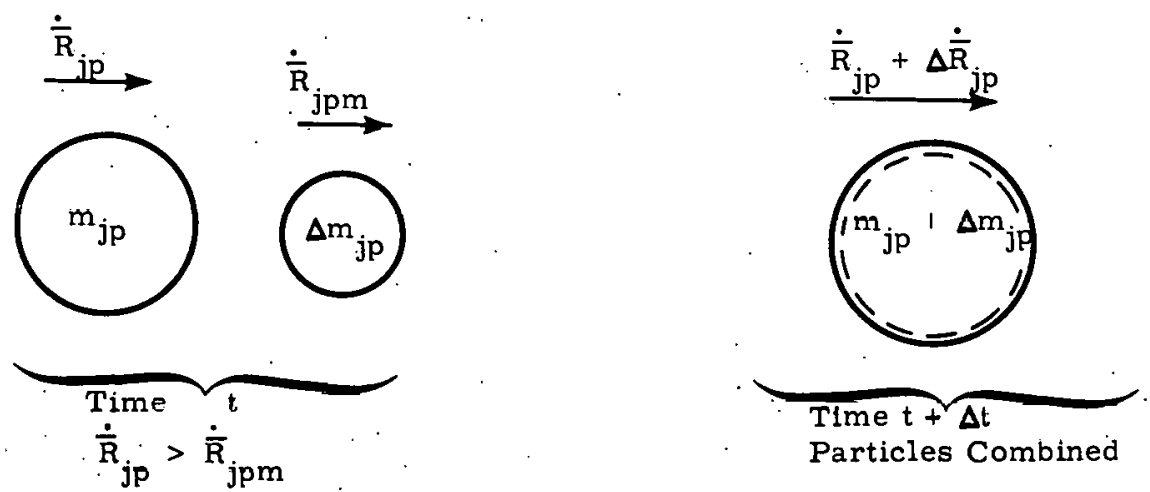

Figure 2. Particle Mass Variation 
At time $t$, the momentum of the particle and approaching mass are given as

$$
\overline{\mathrm{P}}_{j p}-\Delta \overline{\mathrm{P}}_{j p}=\mathrm{m}_{j \mathrm{p}} \dot{\overline{\mathrm{R}}}_{\mathrm{jp}}+\Delta \mathrm{m}_{\mathrm{jp}} \dot{\overline{\mathrm{R}}}_{\mathrm{jpm}}
$$

At time $t+\Delta t$, the two masses have joined. Then the momentum of the combined particle becomes

$$
\overline{\mathrm{P}}_{j \mathrm{p}}=\left(\mathrm{m}_{j p}+\Delta \mathrm{m}_{\mathrm{jp}}\right)\left(\dot{\bar{R}}_{\mathrm{jp}}+\Delta \dot{\overline{\mathrm{R}}}_{j \mathrm{p}}\right) \text {. }
$$

The rate of change of linear momentum for the varying mass particle " $p$ " is obtained by combining Eqs. (6) and (7) into difference form and taking the limit as $\Delta t \rightarrow 0$.

$$
\dot{\mathrm{P}}_{j p}=\lim _{\Delta t \rightarrow 0}\left(\frac{\Delta \overline{\mathrm{P}}_{j p}}{\Delta t}\right)=\mathrm{m}_{j p} \ddot{R}_{j p}+\dot{m}_{j p}\left(\dot{\bar{R}}_{j p}-\stackrel{\perp}{\mathrm{R}}_{j p m}\right) \text {. }
$$

Substituting Eq. (8) into Eq. (3), the force acting on the variable mass particle "p" is given as

$$
\overline{\mathrm{F}}_{j p}=\mathrm{m}_{j \mathrm{p}} \ddot{\overline{\mathrm{R}}}_{\mathrm{jp}}+\dot{\mathrm{m}}_{\mathrm{jp}}\left(\dot{\overline{\mathrm{R}}}_{j p}-\dot{\overline{\mathrm{R}}}_{\mathrm{jpm}}\right)
$$

Equation ( 9 ) indicates that the force acting on a variable mass particle is instantaneousiy equal to the particle mass times acceleration plus the product of the particle mass rate of change and the velocity relative to the particle of the swallowed or exhausted mass. This fundamental equation for varying mass systems, often called the "rocket equation, " can be found in many dynamics texts; e.g., References 1 and 2.

At this point in many derivations, such as those in References 1 and 2, the last term in Fr. (9) is interpreted to be thrust, an external force. Because it then appears instantanenusly that, even for a varying mass system, force equals mass times acceleration, $m_{j p}$ is often thereafter treated as a constant; e.g., the general derivations of References 2 and 3 . When these interpretations are used, many important terms in the force and moment equations are lost.

Thrust is determined by the product of the mass rate of change and the velocity of the exhausted or swallowed mass relative to the point on the body from which the mass was ejected or ingested. Since we are dealing at this point in the derivation with a particle and not with a body, the concept of thrust is premature. For a general derivation, the term $m_{j p}$, like the remaining terms in Eq. (9), must be treated as functions of time.

Differentiating Eqs. (1) and (2) and then substituting the result into Eq. (9), the force acting un the particile "p" can be written as

$$
\bar{F}_{j p}=m_{j p}\left(\ddot{\bar{R}}_{o}+\ddot{\bar{r}}_{j}+\ddot{\bar{\rho}}_{j p}\right)+\dot{m}_{j p}\left[\dot{\bar{\rho}}_{j p}-\left(\dot{\bar{\rho}}_{j m}+\dot{\bar{\rho}}_{j p \Delta m}\right)\right] \text {. }
$$


Substituting Eq. (10) into Eq. (4), the moment of the force $\overline{\mathrm{F}}_{\mathrm{jp}}$ about the origin of the reference $\mathrm{XYZ}$ coordinate system becomes

$$
\overline{\mathrm{M}}_{\mathrm{jp}}=m_{j p}\left(\bar{r}_{j}+p_{j p}\right) \times\left(\ddot{\bar{R}}_{o}+\ddot{\bar{r}}_{j}+\ddot{\bar{\rho}}_{j p}\right)+\ddot{m}_{j p}\left(\bar{r}_{j}+\bar{\rho}_{j p}\right) \times\left[\dot{\bar{\rho}}_{j p}-\left(\dot{\bar{\rho}}_{j m}+\dot{\bar{\rho}}_{j p \Delta m}\right)\right] \text {. }
$$

Note that if the thrust interpretation had been used in Eq. (9), the last terms of Eqs. (10) and (11) would be missing. It will become obvious later in the derivation that not only are thrust induced forces and moments derived from these terms, but so are the jet damping forces and mo: ments and the contributions of varying mass to rate of change of moments and products of inertia.

\section{jth Body Dynamics}

Summing for all of the particles " $p$ " of the $j$ th body, the mass of the body is given as

$$
\sum_{p} m_{j p}=m_{j}
$$

while the mass of an element or slug of the continuous incoming or outgoing mass stream (Figure 1) is

$$
\sum_{p} \Delta m_{j p}=\Delta m_{j}
$$

Differentiating Eq. (12), the rate of change of the $j$ th body's mass is given as

$$
\sum_{\mathrm{p}} \dot{\mathrm{m}}_{\mathrm{jp}}=\dot{\mathrm{m}}_{\mathrm{j}}
$$

The sign of Eq. (13) determines if mass is ejected from or swallowed by the $j$ th body.

The instantaneous cg location of the $j \underline{\text { th }}$ body, obtained by summing particle mass moments about the origin of the $\mathrm{X}_{\mathrm{i}} \mathrm{Y}_{\mathrm{i}} \mathrm{Z}_{\mathrm{i}}$ inertial reference system, can be written as

$$
\sum_{p} m_{j p} \bar{R}_{j p}=m_{j} \bar{R}_{j c g}
$$

where

$$
\bar{R}_{j c g}=\bar{R}_{o}+\bar{r}_{j}+\bar{\rho}_{j c g}
$$

Using Eqs. (1), (12), and (1.5), Eq. (14) can be reduced to

$$
\sum_{p} m_{j p} \bar{\rho}_{j p}=m_{j} \bar{\rho}_{j c g}
$$


Equation (16) is important because it allows the summations of the unknown particle mass moments to be expressed in terms of easily determined paramcters: the mass $m_{j}$ and ey location $\bar{\rho}_{j c g}$ of the $j$ th body. Note that $\bar{\rho}_{j c g}$ is a variable because of the motion of the $j$ th body and also because of the effects of varying mass and varying configuration.

Letting " $c$ " in $\Delta \mathrm{m}_{j}$ (Figure 1) be the cg of the mass slug, the summation of particle mass moments about "c" yields

$$
\sum \Delta \mathrm{m}_{\mathrm{jp}} \bar{\rho}_{\mathrm{jp} \Delta \mathrm{m}}=0
$$

The vector $\bar{R}_{j m}$ then describes the position of the mass slug's cg relative to the origin of the $X_{i} Y_{i} Z_{i}$ inertially fixed axes:

$$
\bar{R}_{j m}=\bar{R}_{o}+\bar{r}_{j}+\bar{\rho}_{j m}
$$

It is assumed for this development that the $\mathrm{cg}$ 's of the exhausted or swallowed mass slugs enter or exit the $\mathrm{j}$ th body at the point located by $\bar{R}_{j e}$. As shown.in Figure 1 and as indicated below, $\bar{R}_{j e}$ is the distance from the origin of the $X_{i} Y_{i} Z_{i}$ inertial reference system to the point at the center of either the nozzle exit plane or inlet entrance plane:

$$
\bar{R}_{j e}=\bar{R}_{o}+\bar{r}_{j}+\bar{p}_{j e}
$$

The velocity of the ejected or swallowed mass slug (velocity of point "c") relative to the reference points at the entrances to or exits from the $\mathrm{j}$ th body is given as

$$
\bar{u}_{j}=\dot{\bar{R}}_{j m}-\dot{R}_{j e}
$$

Substituting the derivatives of Eqs. (18) and (19) into Eq. (20) and then rearranging the result gives

$$
\dot{\bar{\rho}}_{j \mathrm{~m}}=\overline{\mathrm{u}}_{\mathrm{j}}+\dot{\bar{\rho}}_{\mathrm{je}}
$$

The effects of varying mass on the motion of the $\mathrm{j}$ th body are raluser by the mass slug instantaneously entering or exiting the hndy. Therefore, for these equationa, the parameters $\bar{p}_{j \mathrm{~m}}$ and $\dot{\bar{\rho}_{j p}} \Delta \mathrm{m}$ must take on the values that would exist at the entrance to or exit from the body; i. e.,

$$
\bar{p}_{\mathrm{jm}} \rightarrow \bar{\rho}_{\mathrm{jc}}
$$

and

$$
\dot{\bar{\rho}}_{\mathrm{jp} \Delta \mathrm{m}} \rightarrow \dot{\bar{\rho}}_{\mathrm{jp} \Delta \mathrm{e}} \quad
$$


Summing Eqs. (10) and (11) for all particles "p" of the $j$ th body and using Eqs. (21) and (23), the force acting on the $j$ th body and the moment of that force about "o" (Figure 1) are given as

$$
\begin{aligned}
& \bar{F}_{j}=\sum_{p}\left[\bar{F}_{j p}+\dot{m}_{j p} \bar{u}_{j}\right]=\left(\sum_{p} m_{j p}\right)\left(\ddot{\bar{R}}_{o}+\ddot{\bar{r}}_{j}\right)-\left(\sum_{p} \dot{m}_{j p}\right) \dot{\bar{\rho}}_{j e}+\left(\sum_{p} m_{j p} \ddot{\overline{\bar{p}}}_{j p}\right) \\
& +\left(\sum_{\mathrm{p}} \dot{\mathrm{m}}_{\mathrm{jp}} \dot{\bar{\rho}}_{\mathrm{jp}}\right)-\left(\sum_{\mathrm{p}} \dot{\mathrm{m}}_{\mathrm{jp}} \dot{\bar{\rho}}_{\mathrm{jp} \Delta \mathrm{e}}\right) \\
& \overline{\mathrm{M}}_{j_{0}}=\sum_{\mathrm{p}}\left[\overline{\mathrm{M}}_{\mathrm{jp}}+\overline{\mathrm{r}}_{\mathrm{j}} \mathrm{x} \cdot \dot{\mathrm{m}}_{\mathrm{jp}} \overline{\mathrm{u}}_{j}+\dot{\mathrm{m}}_{\mathrm{jp}} \overline{\bar{\rho}}_{\mathrm{jp}} \times\left(\overline{\mathrm{u}}_{\mathrm{j}}+\dot{\bar{\rho}}_{\mathrm{jp} \Delta \mathrm{e}}\right)\right]=\left(\sum_{\mathrm{p}} \mathrm{m}_{j \mathrm{p}} \overline{\bar{\rho}}_{j p} \times \ddot{\bar{\rho}}_{j p}\right) \\
& +\left(\sum_{p} \dot{m}_{j p} \bar{\rho}_{j p} \times \dot{\bar{\rho}}_{j p}\right)+\left[\left(\sum_{\dot{p}} m_{j p}\right) \bar{r}_{j}+\left(\sum_{p} m_{j p} \bar{\rho}_{j p}\right)\right] \times\left(\ddot{\bar{R}}_{o}+\ddot{\bar{r}}_{j}\right) . \\
& +\bar{r}_{j} \times\left[\left(\sum_{p} m_{j p} \ddot{\bar{\rho}}_{j p}\right)+\left(\sum_{p} \dot{m}_{j p} \dot{\bar{\rho}}_{j p}\right)-\left(\sum_{p} \dot{m}_{j p} \dot{\bar{\rho}}_{j p \Delta \theta}\right)\right] \\
& -\left[\left(\sum_{p} \dot{m}_{j p}\right) \bar{r}_{j}+\left(\sum_{p} \dot{m}_{j p} \bar{\rho}_{j p}\right)\right] x \dot{\bar{\rho}}_{j e}
\end{aligned}
$$

Not all of the summations in Eqs. (24) and (25) can be satisfied by Eqs. (12), (13), and (16). Derivatives of Eq. (16) are required to satisfy many. In the following development, an approach described by Meriam ${ }^{5}$ will be used to obtain the necessary derivatives.

At time $t$ the $\mathrm{cg}$ location of the $\mathrm{j}$ th body is given by Eq. (14), while at $t+\Delta t$ the following relation can be used

$$
m_{j} \bar{R}_{j c g}+\Delta\left(m_{j} \bar{R}_{j c g}\right)=\sum_{p} m_{j p}\left(\bar{R}_{j p}+\Delta \bar{R}_{j p}\right)+\sum_{p} \Delta m_{j p}\left(\bar{R}_{j p m}+\Delta \bar{R}_{j p m}\right) \cdot
$$

The first term on the right-hand side of Eq. (26) accounts for the effect on mass moment of variation in position (configuration) of the mass particles which make up the $j$ th body. The second term accounts for the change in mass moment due to the addition or deletion of mass to or from the particles. Combining Eqs. (14) and (26) into difference form, using Eqs. (2), (13), (17), and (18), and taking the limit as $\Delta t \rightarrow 0$,

$$
\frac{d}{d t}\left(m_{j} \cdot \bar{k}_{j c g}\right)=\lim _{\Delta t \rightarrow 0}\left[\frac{\Delta\left(m_{j} \bar{R}_{j c g}\right)}{\Delta t}\right]=\sum_{p} m_{j p} \dot{\bar{n}}_{j p} 1 \dot{m}_{j} \bar{R}_{j m} .
$$

Expanding Dq. (27) and rearranging the result: 


$$
\sum_{\mathrm{p}} \mathrm{m}_{j \mathrm{p}} \dot{\overline{\mathrm{R}}}_{j p}=\mathrm{m}_{\mathrm{j}} \dot{\overline{\mathrm{R}}}_{j \mathrm{jcg}}+\dot{\mathrm{m}}_{\mathrm{j}}\left(\overline{\mathrm{R}}_{j \mathrm{jcg}}-\overline{\mathrm{R}}_{j \mathrm{~m}}\right) \cdot
$$

Combining Eq. (28) with the derivative of Eq. (14):

$$
\sum_{p} \dot{m}_{j p} \bar{R}_{j p}=\dot{\mathrm{m}}_{j} \overline{\mathrm{R}}_{j \mathrm{~m}}
$$

Equations (28) and (29) describe the elements of the particle mass moment summation first derivative. Equation (28) is necessary in order to obtain descriptions of mass moment summation related șecond derivatives, while Eq. (29), as shown later, has direct application in Eq. (25). If $m_{j p}$ had been assumed to be instantaneously constant, the first derivative of the particle mass mument summation, like that of Reference 2, would have consisted only of the first term on the right-hand side of Eq. (28),

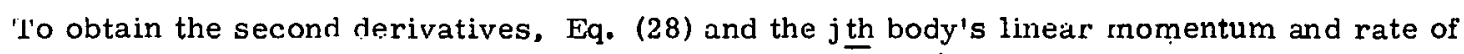
change of linear momentum are used. Summing Eqs. (5) and (8) for all particles " $p$ " of the $j$ th body and using Eqs. (1), (2), (13), and (18)

$$
\begin{aligned}
& \overline{\mathrm{P}}_{j}=\sum_{p} \overline{\mathrm{P}}_{j p}=\sum_{p} \mathrm{~m}_{j p}^{\prime} \dot{\overline{\mathrm{R}}}_{j p} \\
& \dot{\overline{\mathrm{P}}}_{j}=\sum_{p} \dot{\overline{\mathrm{P}}}_{j p}=\sum_{p} m_{j p} \ddot{\overline{\mathrm{R}}}_{j p}+\sum_{p} \dot{\mathrm{m}}_{j p} \dot{\overline{\mathrm{R}}}_{j p}-\sum_{p} \dot{\mathrm{m}}_{j p} \dot{\overline{\bar{\rho}}}_{j p \Delta m}-\dot{\mathrm{m}}_{\mathrm{j}} \dot{\overline{\mathrm{R}}}_{j \mathrm{~m}} .
\end{aligned}
$$

Combining Eqs. (28) and (30), the linear momentum of the jth body can he written as

$$
\bar{P}_{j}=m_{j} \dot{\bar{R}}_{j c g}+\dot{m}_{j}\left(\bar{R}_{j c g}-\bar{R}_{j m}\right) \text {. }
$$

Differentiating Eq. (32) and substituting it into Eq. (31) yields

$$
\sum_{p} m_{j p} \ddot{\bar{R}}_{j p}+\sum_{p} \dot{m}_{j p} \dot{\bar{R}}_{j p}-\sum_{n} \dot{m}_{j p} \dot{\bar{\rho}}_{j p \Delta m}=m_{j} \ddot{\bar{R}}_{j c g}+2 \dot{m}_{j} \dot{\bar{R}}_{j c g}+\ddot{m}_{j}\left(\bar{R}_{j c g}-\bar{R}_{j m}\right),
$$

which can be reduced to the required particle mass moment summation second derivatives.

Substituting Eqs. (1), (15), (18), and their derivatives along with Eqs. (12), (13), (22), and (23) as needed into Eqs. (29) and (33), the particle mass moment summation derivatives of intcrest can be expressed as

$$
\sum_{p} \dot{m}_{j p} \bar{\rho}_{j p}=\dot{m}_{j} \bar{\rho}_{j e}
$$




$$
\sum_{p} m_{j p} \ddot{\bar{\rho}}_{j p}+\sum_{p} \dot{m}_{j p} \dot{\bar{\rho}}_{j p}-\sum_{p} \dot{m}_{j p} \dot{\bar{\rho}}_{j p \Delta m}=m_{j} \ddot{\bar{\rho}}_{j c g}+2 \dot{m}_{j} \dot{\bar{\rho}}_{j c g}+\ddot{m}_{j}\left(\bar{\rho}_{j c g}-\bar{\rho}_{j e}\right)+\dot{m}_{j}\left(\dot{\bar{R}}_{o}+\dot{\bar{r}}_{j}\right)
$$

Using Eq. (13), the summation involving $\bar{u}_{j}$ in the applied force term of Eq. (24) can be written as

$$
\left(\sum_{p} \dot{m}_{j p}\right) \bar{u}_{j}=\dot{m}_{j} \bar{u}_{j}=\bar{T}_{j}
$$

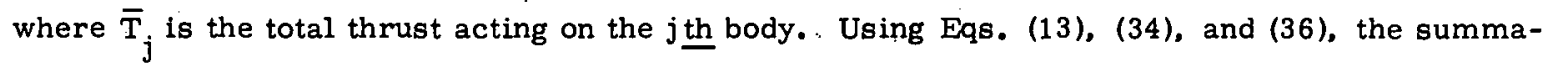
tions involving $\bar{u}_{j}$ in the applied moment term of Eq. (25) become

$$
\begin{gathered}
\bar{r}_{j} \times\left(\sum_{p} \dot{m}_{j p}\right) \bar{u}_{j}=\bar{r}_{j} \times \dot{m}_{j} \dot{\mathrm{u}}_{j}=\bar{r}_{j} \times \overline{\mathrm{T}}_{j} . \\
\left(\sum_{p} \dot{\mathrm{m}}_{j p} \bar{\rho}_{j p}\right) \times \bar{u}_{j}=\bar{\rho}_{j \mathrm{e}} \times \dot{\mathrm{m}}_{\mathrm{j}} \bar{u}_{j}=\bar{\rho}_{\mathrm{je}} \times \overline{\mathrm{T}}_{\mathrm{j}} .
\end{gathered}
$$

Substituting Eq. (36) into Eq. (24), the applied force acting on the $j$ th body can be described by

$$
\bar{F}_{j}=\sum_{\mathbf{p}} \bar{F}_{j p}+\dot{\mathrm{T}}_{j}
$$

Substituting Eqs. (37) and (38) into Eq. (25), the applied moment becomes

$$
\overline{\mathrm{M}}_{j_{0}}=\sum_{\mathrm{p}} \overline{\mathrm{M}}_{\mathrm{jp}}+\left(\overline{\mathrm{r}}_{j}+\bar{\rho}_{\mathrm{je}}\right) \times \overline{\mathrm{T}}_{\mathrm{j}}+\sum_{\mathrm{p}} \dot{\mathrm{m}}_{\mathrm{jp}} \bar{\rho}_{\mathrm{jp}} \times \dot{\bar{\rho}}_{\mathrm{jp} \Delta \mathrm{e}}
$$

Because thrust is an external force, hereafter, as indicated by Eqs. (39) and (40), its contribution to applied force and moment will be included in $\bar{F}_{j}$ and $\bar{M}_{j_{0}}$ : respectively, without being
indicated separately.

Equation (38) describes the thrust misalignment moment which acts about the origin of the $\mathrm{X}_{j} \mathrm{Y}_{\mathrm{j}} \mathrm{Z}_{\mathrm{j}}$ body-fixed axis system. The sum of Eqs. (37) and (38), the second term on the right-hand side of Eq. (40), represents the total moment of the thrust force acting about "o" (Figure 1).

The first terms on the right-hand sides of Eqs. (39) and (40), the particle force and moment summations, include only contributions due to external force and gravitational force. The particle interaction forces do not contribute anything because they occur in pairs of equal but opposite forces. Since the external forces (aerodynamic force, interaction force from other bodies, etc.) and the gravitational force acting on the $j$ th body can be directed along lines which do not include the origin of the $X_{j} Y_{j} Z_{j}$ body-fixed axes, their resulting moments in Eq. (40), like the thrust 
induced moments, can consist of a portion acting about the origin of the $X_{j} Y_{j} Z_{j}$ axes and a portion consisting of the vector product of $\bar{r}_{j}$ and the external and gravitational forces.

The last term on the right-hand side of Eq. (40) is a mass variation induced couple. This moment results from particle mation within the incoming or outgoing mass slug; therefore, knowledge concerning these particle motions is required for its evaluation. The presence of this moment indicates that the motion of the $j \underline{\text { th }}$ body can be affected by motions of the mass slug other than those responsible for the thrust force; therefore the often used treatment of the mass slug as a point mass is incorrect. Because it can have compensating effects, this moment should not be neglected under conditions where the moment resulting from mass variation induced rates of change of moments and products of inertia is considered to be important. Like the particle moment summation and thrust induced moments, as indisated by $F_{f}$. $(4 n)$, the mass variation induood couple will be included in $\mathrm{M}_{\mathbf{j}_{0}}$.

Substituting Eqs. (12), (13), (16), (34), and (35) into Eqs. (24) and (25), the force acting on the $\mathrm{j}$ th body and its moment about "o" become

$$
\begin{aligned}
& \bar{F}_{j}=\frac{d}{d t}\left[m_{j}\left(\dot{\bar{R}}_{o}+\dot{\bar{r}}_{j}+\dot{\bar{\rho}}_{j c g}\right)\right]+\dot{\mathrm{m}}_{j}\left(\dot{\bar{\rho}}_{j c g}-\dot{\bar{\rho}}_{j e}\right)+\ddot{m}_{j}\left(\bar{\rho}_{j c g}-\bar{\rho}_{j e}\right) \text {. } \\
& \bar{M}_{j o}=\dot{\bar{H}}_{j}+m_{j}\left(\bar{r}_{j}+\bar{\rho}_{j c g}\right) x\left(\ddot{\bar{R}}_{o}+\ddot{\bar{r}}_{j}\right)+m_{j} \bar{r}_{j} \times \ddot{\bar{\rho}}_{j c g} \\
& +\dot{\mathrm{m}}_{\mathrm{j}} \overline{\mathrm{r}}_{\mathrm{j}} \mathrm{x}\left(\dot{\overline{\mathrm{R}}}_{\mathrm{o}}+\dot{\mathrm{r}}_{\mathrm{j}}+2 \dot{\overline{\bar{\rho}}}_{\mathrm{jcg}}-\dot{\bar{\rho}}_{\mathrm{je}}\right)-\dot{\mathrm{m}}_{\mathrm{j}} \bar{\rho}_{j \mathrm{j}} \mathrm{x} \dot{\bar{\rho}}_{j e}+\ddot{\mathrm{m}}_{\mathrm{j}} \overline{\mathrm{r}}_{\mathrm{j}} \times\left(\bar{\rho}_{j c g}-\bar{\rho}_{j e}\right)
\end{aligned}
$$

wliei'e

$$
\overline{\mathrm{H}}_{j}=\left(\sum_{\mathrm{p}} \mathrm{m}_{j p} \bar{\rho}_{j p} \times \dot{\bar{\rho}}_{j p}\right)
$$

is the apparent moment of momentum of the $j$ th body to an observer fixed in the $X_{j} Y_{j} 7_{j}$ rnnrdinate system. As shown later, the vector $\overline{\mathrm{H}}_{j}$ is partially defined in terms of the jth body's moments and products of inertia.

The mass variation induced jet damping forces and moments, those terms involving $\dot{\mathrm{m}}_{\mathrm{j}}$, $\bar{\rho}_{j e}$, and their first derivatives, are apparent in Eqs. (41) and (42). Because the cg is not necessarily located at the origin of the $\mathrm{X}_{j} \mathrm{Y}_{j} \mathrm{Z}_{j}$ body-fixed axes, corrections to these forces and moments exist in these equations. One moment correction is contained in $\dot{\bar{H}}_{j}$, while the remaining corrections are provided by some of the terms involving $\dot{\mathrm{m}}_{\mathrm{j},} \bar{\rho}_{\mathrm{jcg}}$ and their first derivatives. 
At this point, equations have been developed which describe the motion of the $j$ th body using vector quantities resolved relative to the $X_{i} Y_{i} Z_{i}$ inertially fixed directions. To accomplish the objectives of this derivation, the vector quantities must be resolved relative to the XYZ reference coordinate directions. Since the XYZ reference axes rotate with angular velocity $\vec{\Omega}$ (Figure 1 ) relative to inertial space, the following replacements for the derivatives in Eqs. (41) and (42) are required.

$$
\begin{aligned}
& \dot{\overline{\mathrm{H}}}_{j}=\dot{\overrightarrow{\mathrm{H}}}_{j}+\overrightarrow{\mathrm{\Omega}} \times \overrightarrow{\mathrm{H}}_{j} \\
& \dot{\bar{r}}_{j}=\dot{\vec{r}}_{j}+\vec{\Omega} \times \vec{r}_{j} \\
& \ddot{\bar{r}}_{j}=\ddot{\vec{r}}_{j}+\dot{\vec{\Omega}} \times \vec{r}_{j}+2 \vec{\Omega} \times \dot{\vec{r}}_{j}+\vec{\Omega} \times\left(\vec{\Omega} \times \vec{r}_{j}\right) \\
& \dot{\bar{p}}_{j c g}=\dot{\vec{\rho}}_{j c g}+\vec{\Omega} \times \vec{\rho}_{j c g} \\
& \ddot{\bar{\rho}}_{j c g}=\ddot{\vec{\rho}}_{j c g}+\dot{\vec{\Omega}} \times \vec{\rho}_{j c g}+2 \vec{\Omega} \times \dot{\vec{\rho}}_{j c g}+\ddot{\vec{\Omega}} \times\left(\vec{\Omega} \times \vec{\rho}_{j c g}\right) \\
& \dot{\bar{\rho}}_{\mathrm{je}}=\dot{\vec{\rho}}_{\mathrm{je}}+\vec{\Omega} \times \vec{\rho}_{j e} \\
& \dot{\mathrm{R}}_{\mathrm{o}}=\overline{\mathrm{V}}
\end{aligned}
$$

Resolving the velocity vector $\bar{V}$ (velocity of "o") relative to the $X X Z$ reference directions and. taking its derivative gives

$$
\ddot{\bar{R}}_{0}=\dot{\vec{V}}+\vec{\Omega} \times \vec{V}
$$

Equations (44) through (50) indicate the equivalence of magnitude and direction shared by the vector quantities on either side of the equal signs; however, note that the vector components on opposing sides of these equations are resolved relative to different coordinates.

Substituting. as needed, Eqs.( (44) through (50) into Eqs. (41) and (42) and then transforming the remaining vectors, the equations of motion for the $j$ th body can be written relative to the $X Y Z$ reference coordinates as

$$
\vec{F}_{j}=m_{j}\left\{\dot{\vec{v}}+\vec{\Omega} \times \vec{v}+\left(\ddot{\vec{r}}_{j}+\ddot{\vec{\rho}}_{j c g}\right)+\dot{\vec{\Omega}} \times\left(\vec{r}_{j}+\vec{\rho}_{j c g}\right)\right.
$$




$$
\begin{aligned}
& \left.+2 \vec{\Omega} \times\left(\dot{\vec{r}}_{j}+\dot{\vec{\rho}}_{j c g}\right)+\vec{\Omega} \times\left[\vec{\Omega} \times\left(\overrightarrow{\mathrm{r}}_{j}+\vec{\rho}_{j c g}\right)\right]\right\} \\
& +\dot{m}_{j}\left\{\vec{v}+\left(\dot{\vec{r}}_{j}+2 \dot{\vec{\rho}}_{\mathrm{jcg}}-\vec{\rho}_{\mathrm{je}}\right)+\vec{\Omega} \times\left(\overrightarrow{\mathrm{r}}_{\mathrm{j}}+2 \vec{\rho}_{\mathrm{jcg}}-\vec{\rho}_{\mathrm{je}}\right)\right\} \\
& +\ddot{m}_{j}\left(\vec{\rho}_{j c g}-\vec{\rho}_{j e}\right) \text {. } \\
& \vec{M}_{j_{0}}=\dot{\overrightarrow{\mathrm{H}}}_{j}+\vec{\Omega} \times \overrightarrow{\mathrm{H}}_{j}+\mathrm{m}_{j}\left(\overrightarrow{\mathrm{r}}_{j}+\vec{\rho}_{j c g}\right) \times\left[\dot{\overrightarrow{\mathrm{V}}}+\vec{\Omega} \times \overrightarrow{\mathrm{V}}+\ddot{\overrightarrow{\mathrm{r}}}_{\mathrm{j}}\right. \\
& \left.+\dot{\vec{\Omega}} \times \vec{r}_{j}+2 \vec{\Omega} \times \dot{\vec{r}}_{j}+\vec{n} \times\left(\vec{\Omega} \times \vec{r}_{j}\right)\right]+m_{j} \vec{r}_{j} \times\left[\ddot{\vec{\rho}}_{j \cup y}\right. \\
& \left.+\dot{\vec{\Omega}} \times \vec{\rho}_{\text {jcg }}+2 \vec{\Omega} \times \dot{\vec{\rho}}_{\mathrm{jcg}}+\vec{\Omega} \times\left(\vec{\Omega} \times \vec{\rho}_{\mathrm{jcg}}\right)\right]+\dot{\mathrm{m}}_{\mathrm{j}} \overrightarrow{\mathrm{r}}_{\mathrm{j}} \times[\overrightarrow{\mathrm{V}} \\
& \left.+\dot{\vec{r}}_{j}+2 \dot{\vec{\rho}}_{j c g}-\dot{\vec{\rho}}_{j e}+\vec{\Omega} \times\left(\vec{r}_{j}+2 \vec{\rho}_{j c g}-\vec{\rho}_{j e}\right)\right]-\dot{m}_{j} \vec{\rho}_{j e} \times \dot{\vec{\rho}}_{j e} \\
& -\dot{m}_{j} \vec{\rho}_{j e} \times\left(\vec{\Omega} \times \vec{\rho}_{j e}\right) ; \quad \ddot{m}_{j} \vec{r}_{j} \times\left(\vec{\rho}_{j c g}-\vec{\rho}_{j e}\right) \text {. }
\end{aligned}
$$

It is assumed that the forces and moments acting on the $j$ th body and the vector quantities which depend on the physical properties of the $j$ th body will be initially defined relative to the $\mathrm{X}_{j} \mathrm{Y}_{j} Z_{j}$ body fixed coordinate system, Therefore. the vectors $\vec{F}_{j *} \vec{M}_{j}, \vec{H}_{j}, \vec{\rho}_{j c} \dot{g}$, and $\vec{\rho}_{j e}$ that appeaiin the preceding equations are obtained by transforming $\hat{F}_{j}, \hat{\vec{M}}_{j}, \hat{H}_{j}, \hat{\rho}_{j c g}$ and $\hat{o}_{j e}$. A generalized. form of the required angular transformation is given as

$$
\left\{\hat{A}_{j}\right\}=\left[\ell_{j}\right]\left\{\hat{A}_{j}\right\} \quad
$$

which when expanded becomes

$$
\left\{\begin{array}{c}
{ }^{A} X_{j} \\
A_{Y_{j}} \\
A_{Z_{j}}
\end{array}\right\}=\left[\begin{array}{ccc}
\ell_{j 11} & l_{j 12} & l_{j 13} \\
\ell_{j 21} & \ell_{j 22} & \ell_{j 23} \\
\ell_{j 31} & \ell_{j 32} & \ell_{j 33}
\end{array}\right]\left\{\begin{array}{l}
A^{A} X_{j j} \\
A Y_{j j} \\
A_{Z_{j j}}
\end{array}\right\}
$$

Here, components of a vector quantity resolyed relative to the body-fixed coordinates $\left(\hat{A}_{j}=A_{X_{i . j}}{ }^{1}{ }+A_{Y_{j j}}{ }_{j}+A_{Z_{j j}}{ }^{k}\right)$ are transformed into components of the same vector quantity 
relative to the $X Y Z$ reference coordinates $\left(\vec{A}_{j}=A_{X_{j}}{ }^{1}+A_{Y_{j}}{ }^{j}+A_{Z_{j}}{ }^{k}\right)$. The direction cosine elements $\ell_{j 11}, \ell_{j 12}$, etc., of the transformation matrix $[\mathrm{Eq},(53)]^{j}$ are defined using Euler rotation sequences, ${ }^{2}$ quaternions, ${ }^{6}$ etc. An abbreviated vector notation indicating the transformation is given as

$$
\vec{A}_{j}=\left[\vec{l}_{j}\right]\left\{\hat{A}_{j}\right\}
$$

where

$$
\left[\overrightarrow{l_{j}}\right]=\left[\begin{array}{ccc}
i & 0 & 0 \\
0 & j & 0 \\
0 & 0 & k
\end{array}\right] \quad\left[\begin{array}{ccc}
\ell_{j 11} & \ell_{j 12} & \ell_{j 13} \\
l_{j 21} & \ell_{j 22} & \ell_{j 23} \\
\ell_{j 31} & \ell_{j 32} & \ell_{j 33}
\end{array}\right]
$$

Using. Eq. (54), the transformed vector quantities appearing in Eq́s. (51) and (52) are defined as

$$
\begin{aligned}
& \vec{F}_{j}=\left[\vec{l}_{j}\right]\left\{\hat{F}_{j}\right\} \\
& \overrightarrow{\mathrm{M}}_{j_{0}}=\left[\vec{l}_{j}\right]\left\{\hat{\mathrm{M}}_{j_{0}}\right\} \\
& \overrightarrow{\mathrm{H}}_{\mathrm{j}}=\left[\vec{l}_{\mathrm{j}}\right]\left\{\hat{\mathrm{H}}_{\mathrm{j}}\right\} \\
& \vec{\rho}_{j c g}=\left[\vec{l}_{j}\right]\left\{\hat{\rho}_{j c g}\right\} \\
& \vec{\rho}_{\mathrm{je}}=\left[\vec{l}_{\mathrm{j}}\right]\left\{\hat{\rho}_{\mathrm{je}}\right\} \text {. }
\end{aligned}
$$

To develop an expression for the apparent moment of momentum $\hat{H}_{j}$ in terms of physical. properties of the $j$ th body, Eq. (43) is written as

$$
\hat{\mathrm{H}}_{\mathrm{j}}=\sum_{\mathrm{p}} \mathrm{m}_{j \mathrm{p}} \hat{\boldsymbol{\rho}}_{\mathrm{jp}} \times \dot{\hat{\rho}}_{\mathrm{jp}}+\sum_{p} \mathrm{~m}_{j p} \dot{\rho}_{j p} \times\left(\hat{\omega}_{j} \times \hat{\rho}_{j p}\right)
$$

where $\hat{\omega}_{j}$ (Figure 1 ) is the angular velocity relative to inertial space of the $x_{j} Y_{j} z_{j}$ body fixed coordinates. As demonstrated in Reference 7, the last summation term in Eq. (60) can be represented in terms of products of the rotational inertia properties of the $j$ th body (moments and products of inertia) and components of $\hat{\omega}_{j}$. The first summation term of Eq. (60) involves terms that have similarities to those portions of the rates of change of product of inertia which result from changes in configuratlon. Eyualion $(G 0)$ can be rewritton $a b$ 


$$
\hat{\mathrm{H}}_{j}=\hat{\mathscr{Z}}_{\mathrm{j}}+\hat{\mathscr{F}}_{\mathbf{j}} \cdot \hat{\omega}_{j}
$$

where the vector

$$
\hat{z}_{j}=\sum_{p} \mathrm{~m}_{\mathrm{jp}} \hat{\rho}_{\mathrm{jp}} \times \dot{\hat{\rho}}_{\mathrm{jp}}
$$

and

$$
\hat{\hat{g}}_{j} \cdot \hat{\omega}_{j}=\sum_{p} m_{j p} \hat{\rho}_{j p} \times\left(\hat{\omega}_{j} \times \hat{\rho}_{j p}\right)=\int_{j \underline{t h b o d y}} \hat{\rho}_{j p} \times\left(\hat{\omega}_{j} \times \hat{\rho}_{j p}\right) d m .
$$

The Inertia dyadic for the $\mathrm{j}$ th body is given as

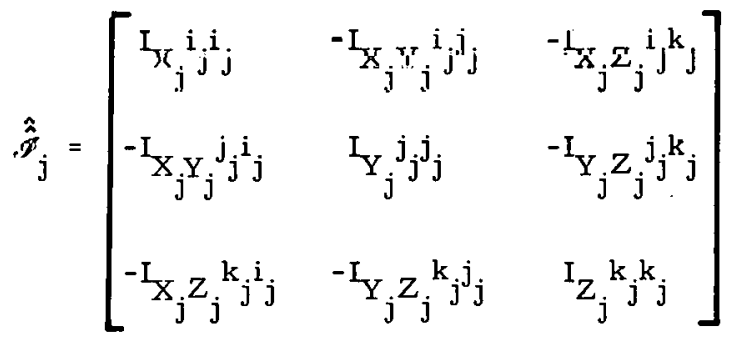
Its elements, the moments and products of inertia $\mathrm{L}_{X_{j}} \mathrm{I}_{\mathrm{X}_{j} \mathrm{Y}_{j}}$, etc.. vary with time due to changes
in mass and configuration.

The $\mathscr{T}_{j}$ term in Eq. (61) can become nonzero when there is particle motion relative to the $X_{j} Y_{j} Z_{j}$ body-fixed axes. This term is difficult to evaluate because individual particle trajectory information is required. Sometimes it is possible to place the body-fixed coordinates within the body so that $\hat{H}_{j}$ is eliminated. For example, this term becomes approximately zero when there exists an even distribution of particles that have particular symmetrical motion patterns, like radial motion, parallel motion, etc., relative to a body-fixed axis system. However, certain symmetrical motions of evenly distributed particles, like swirling motion, can cause the term to be nonzero. Fortunately, for many problems of interest, detailed evaluation of $\hat{h}_{j}$ is not required because it is negligibly small in comparison to the remaining term in Eq. (61).

Note that the following derivatives of Eqs. (57) through (59) and Eq. (61) are required in Eqs. (51) and (52).

$$
\begin{aligned}
& \dot{\vec{H}}=\left[\vec{D}_{J}\right]\left\{\dot{\hat{H}}_{j}\right\}+\left[\dot{\vec{l}}_{j}\right]\left\{\hat{\mathrm{H}}_{\mathrm{j}}\right\} \\
& \dot{\hat{\mathrm{H}}}=\dot{\mathscr{\partial}}_{\mathrm{j}}+\dot{\mathscr{I}}_{\mathrm{j}} \cdot \dot{\hat{\omega}}_{\mathrm{j}}+\dot{\hat{\mathscr{I}}}_{\mathrm{j}} \cdot \hat{\omega}_{\mathrm{j}}
\end{aligned}
$$




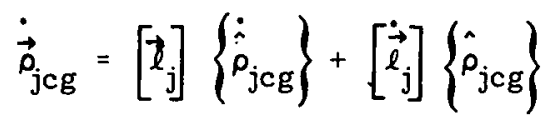

$$
\begin{aligned}
& \ddot{\vec{\rho}}_{j c g}=\left[\vec{l}_{j}\right]\left\{\ddot{\hat{\rho}}_{j c g}\right\}+2\left[\ddot{\vec{l}}_{j}\right]\left\{\dot{\hat{\hat{\rho}}}_{j c g}\right\}+\left[\ddot{\vec{l}}_{j}\right]\left\{\hat{\hat{\rho}}_{j c g}\right\} \\
& \dot{\vec{\rho}}_{\mathrm{je}}=\left[\vec{l}_{\mathrm{j}}\right]\left\{\dot{\hat{\rho}}_{\mathrm{je}}\right\}+\left[\dot{\vec{l}}_{\mathrm{j}}\right]\left\{\hat{\hat{\rho}}_{\mathrm{je}}\right\} .
\end{aligned}
$$

Inspecting Eqs. (51) and (52), together with Eqs. (55) through (67), it becomes obvious that for variable mass bodies many time varying parameters must be specified before Eqs. (51) and (52) can be used. These parameters are listed below:

$$
\begin{aligned}
& \mathrm{m}_{j}, \dot{\mathrm{m}}_{j}, \mathrm{~m}_{j} \\
& \phi_{\mathrm{je}}, \dot{\phi}_{\mathrm{je}} \\
& \hat{\rho}_{j c g}, \dot{\hat{\hat{\rho}}}_{\mathrm{jcg}}, \ddot{\hat{\hat{\rho}}}_{\mathrm{jcg}} \\
& I_{x_{j}} \cdot \dot{I}_{x_{j}} \\
& \mathrm{I}_{\mathrm{Y}}, \dot{\mathrm{I}}_{\mathrm{Y}_{j}} \\
& I_{z_{j}} \cdot \dot{I}_{z_{j}} \\
& L_{X_{j}} Y_{j} \cdot \dot{L}_{X_{j} Y_{j}} \\
& \mathrm{~L}_{j} Z_{j}, \dot{\mathrm{L}}_{\mathrm{j}} Z_{j} \\
& \mathrm{I}_{\mathrm{j}} z_{j} \cdot \dot{\mathrm{L}}_{\mathrm{x}_{j} z_{j}} \\
& \hat{\not}_{j}, \dot{y}_{j} \\
& \hat{F}_{j}, \hat{M}_{j o}
\end{aligned}
$$


To use Eqs. (51) and (52) for variable configuration bodies, the same list of parameters must be specified with the exception of $m_{j}, \hat{\rho}_{j e}$, and their time dcrivatives. For rigid bodies; only $\hat{F}_{j}$ and $\hat{\mathrm{M}}_{\mathrm{j}}$ must be specified as functions of time since all of the remaining parameters in the list are either constant or zero.

Estimates of the above listed parameters will most likely be used in place of exact evaluations. The exact time variations of many of these parameters would be practically impossible to obtain since knowledge concerning the trajectories of individual particles within the moving body would be required.

\section{System Dynamics}

The total mass of the system of $\mathrm{j}$ hodies and the $\mathrm{cg}$ location of that system relative to the inertially flxed $X_{1} Y_{1} Z_{i}$ coordinates (Figure 1) are found by summing the masses of the $j$ bodies and their mass moments as follows:

$$
\begin{aligned}
& \sum_{j} m_{j}=m \\
& \sum_{j} m_{j} \bar{R}_{j c g}=m \bar{R}_{c g}
\end{aligned}
$$

where

$$
\bar{R}_{c g}=\bar{R}_{o}+\bar{r}_{c g}
$$

Differentiating Fr. (68)

$$
\sum_{j} \dot{\mathrm{m}}_{j}=\dot{\mathrm{m}}
$$

Substituting Eqs. (15) and (70) into Eq. (69) and then resolving vectors relative to the XYZ rel'erence cuordinate frame, the cg location of the system of bodies relative to the origin " 0 " of. the reference $\mathrm{XYZ}$ coordinates (Figure 1 ) is given as

$$
\sum_{j} m_{j}\left(\vec{r}_{j}+\vec{\rho}_{j c g}\right)=\vec{r}_{c g}
$$

The total force acting on the system of bodies and the moment of that force about " 0 " a re obtained by summing Eqs. (51) and (52) for all j bodies and using Eqs. (68), (71), and (72) 


$$
\begin{aligned}
& \vec{F}=\sum_{j} \vec{F}_{j}=m(\dot{\vec{v}}+\vec{\Omega} \times \vec{v})+\dot{m} \vec{v}+\dot{\vec{\Omega}} \times \overrightarrow{m r}_{c g} \\
& +\vec{\Omega} \times\left(\vec{\Omega} \times m \vec{r}_{c g}\right)+\left(\sum_{j} m_{j}\left(\ddot{\vec{r}}_{j}+\overrightarrow{\vec{\rho}}_{j c g}\right)\right)+2 \vec{\Omega} \times\left(\sum_{j} m_{j}\left(\overrightarrow{\vec{r}}_{j}+\vec{\rho}_{j c g}\right)\right) \\
& +\left(\sum_{j} \dot{m}_{j}\left(\dot{\vec{r}}_{j}+\dot{\vec{p}}_{j c g}-\dot{\vec{p}}_{j e}\right)\right)+\vec{\Omega} \times\left(\sum_{j} \dot{m}_{j}\left(\vec{r}_{j}+2 \vec{\rho}_{j c g}-\vec{\rho}_{j e}\right)\right) \\
& +\left(\sum_{j} \ddot{m}_{j}\left(\vec{\rho}_{j c g}-\vec{\rho}_{j e}\right)\right) \text {. } \\
& \overrightarrow{\mathrm{M}}_{\mathrm{o}}=\sum_{j} \overrightarrow{\mathrm{M}}_{j_{0}}=\left(\sum_{j} \dot{\vec{H}}_{j}\right)+\vec{\Omega} \times\left(\sum_{j} \vec{H}_{j}\right)+\overrightarrow{\mathrm{mr}}_{\mathrm{cg}} \times[\overrightarrow{\vec{v}}+\vec{\Omega} \mathrm{x} \overrightarrow{\vec{v}}] \\
& +\left(\sum_{j} m_{j}\left(\vec{r}_{j}+\vec{p}_{j c g}\right) \times \ddot{\vec{r}}_{j}\right)+\left(\sum_{j} m_{j}\left(\vec{r}_{j}+\overrightarrow{\vec{p}}_{j c g}\right) \times\left(\dot{\vec{\Omega}} \cdot \times \vec{r}_{j}\right)\right) \\
& +2\left(\sum_{j} m_{j}\left(\vec{r}_{j}+\vec{\rho}_{j c g}\right) \times\left(\vec{\Omega} \times \dot{\vec{r}}_{j}\right)\right)+\left(\sum_{j} m_{j}\left(\vec{r}_{j}+\vec{\rho}_{j c g}\right) \times\left[\vec{\Omega} \times\left(\vec{\Omega} \times \vec{r}_{j}\right)\right]\right) \\
& +\left(\sum_{j} m_{j} \vec{r}_{j} \times \ddot{\vec{\rho}}_{j c g}\right)+\left(\sum_{j} m_{j} \vec{r}_{j} \times\left(\vec{\Omega} \times \vec{\rho}_{j c g}\right)\right)+2\left(\sum_{j} m_{j} \vec{r}_{j} \times\left(\vec{\Omega} \times \dot{\vec{\rho}}_{j c g}\right)\right)(74) \\
& +\left(\sum_{j} m_{j} \vec{r}_{j} \times\left[\vec{\Omega} \times\left(\vec{\Omega} \times \vec{\rho}_{j c g}\right)\right]\right)+\left(\sum_{j} \dot{m}_{j} \vec{r}_{j} \times\left(\dot{\vec{r}}_{j}+2 \dot{\vec{\rho}}_{j c g}-\dot{\vec{\rho}}_{j \mathrm{je}}\right)\right) \\
& +\left(\sum_{j} \dot{m}_{i} \vec{r}_{j} \times\left[\vec{\Omega} \times\left(\vec{r}_{j}+2 \vec{\rho}_{j e g}-\vec{\rho}_{j e}\right)\right]\right)+\left(\sum_{j} \dot{m}_{j} \vec{r}_{j} \times \vec{v}\right) \\
& -\left(\sum_{j} \dot{m}_{j} \vec{\rho}_{j e} \times \dot{\vec{\rho}}_{j e}\right)-\left(\sum_{j} \dot{m}_{j} \vec{\rho}_{j e} \times\left(\vec{\Omega} \times \vec{\rho}_{j e}\right)\right)+\left(\sum_{j} \ddot{m}_{j} \vec{r}_{j} \times\left(\vec{\rho}_{j c g}-\vec{\rho}_{j e}\right)\right) .
\end{aligned}
$$

27 
Motions of the $\mathrm{j}$ individual bodies are described by Eqs. (51) and (52), together with their auxiliary equations, while Eqs. (73) and (74) describe the motion of the systcm of $j$ bodies. Unless the relative motions of the bodies have been specified a priori, equations from both sets are required to solve a multiple body problem.

The forces and moments acting on the $j$ individual bodies include those resulting from gravitational forces, body interaction forces, and other external forces such as thrust and aerodynamic force. Forces and moments resulting from body interactions occur in pairs whose contributions are equal in magnitude but opposite in sign. Therefore, in the summation to obtain Eqs. (73) and (74), the contributions to these pairs cancel, leaving only the summations of the remaining external forces and moments and gravitational forces and moments, which are represented by $\vec{F}_{\text {and }} \vec{M}_{0}$.

\section{Example Cases}

In order to demonstrate the usefulness of these general equations of motion, two examples will be given. For the first example, equations of motion will be developed relative to a nonrolling coordinate system (aeroballistic axes) for a spinning-thrusting vehicle containing an internal rotating mass. The equations of motion for a spinning-thrusting combination of bodies having a flexible joint will be developed as a second example.

\section{Rotating Internal Mass}

The two-body system considered here (Figure 3 ) consists of an outer spinning-variable mass (thrusting) body which contains an inner rigid body that spins at a different rate. For this example, the $\mathrm{X}_{1} \mathrm{Y}_{1} \mathrm{Z}_{1}$ coordinate system is fixed in Body 1 with its origin located away from the cg of the body $\left(\hat{\rho}_{\text {lc }}=\mathrm{x}_{\mathrm{r} g}, 0,0\right)$, whilc the $\mathrm{X}_{P_{1}} \mathrm{Y}_{2} \mathrm{Z}_{2}$ coordinate frame is lixed in Body 2 with its origin at the body's $\mathrm{cg}\left(\hat{\rho}_{2 \mathrm{cg}}=0\right)$. Note that the $\dot{c} \mathrm{~g}$ of Body 1 and Body 2 lie on the common axis of symmetry of these bodies. As shown in Figure 3, the colinear $X_{1}$ and $X_{2}$ axes are directed toward the nose of Body 1 along the axis of symmetry. The position of $Y_{2}$ relative to $Y_{1}$ and $Z_{2}$ relative to $Z_{1}$ is described by the angle $\gamma$.

'I'he XYZ nonrolling reference coordinate system (Figure 3 ) is placed in this system of bodies so that its origin " 0 " is coincident with the origin of the $X_{1} Y_{1} Z_{1}$ body fixed axes $\left(\hat{r}_{1}=0 . \hat{r}_{2}=x_{2} n_{i}\right.$ $0)$. The $X_{1}$ and $X$ axes, which have identical direction. remain snlinear while the position of $Y_{1}$ relative to $Y$ and $Z_{1}$ relative to $Z$ is described by the roll angle $\phi$. Therefore, like Body 2 , the reference coordinate system pitches and yaws with Body 1 but does not roll with it.

For the arrangement of coordinate systems and constraints pictured in Figure 3 , the equations of motion for the system of bodies, Eq. (52) together with Eqs. (68) and (71) through (74), reduce to the following vector set

$$
\vec{r}_{c g}=m_{1} \vec{R}_{c g}+m_{2} \vec{r}_{2}
$$



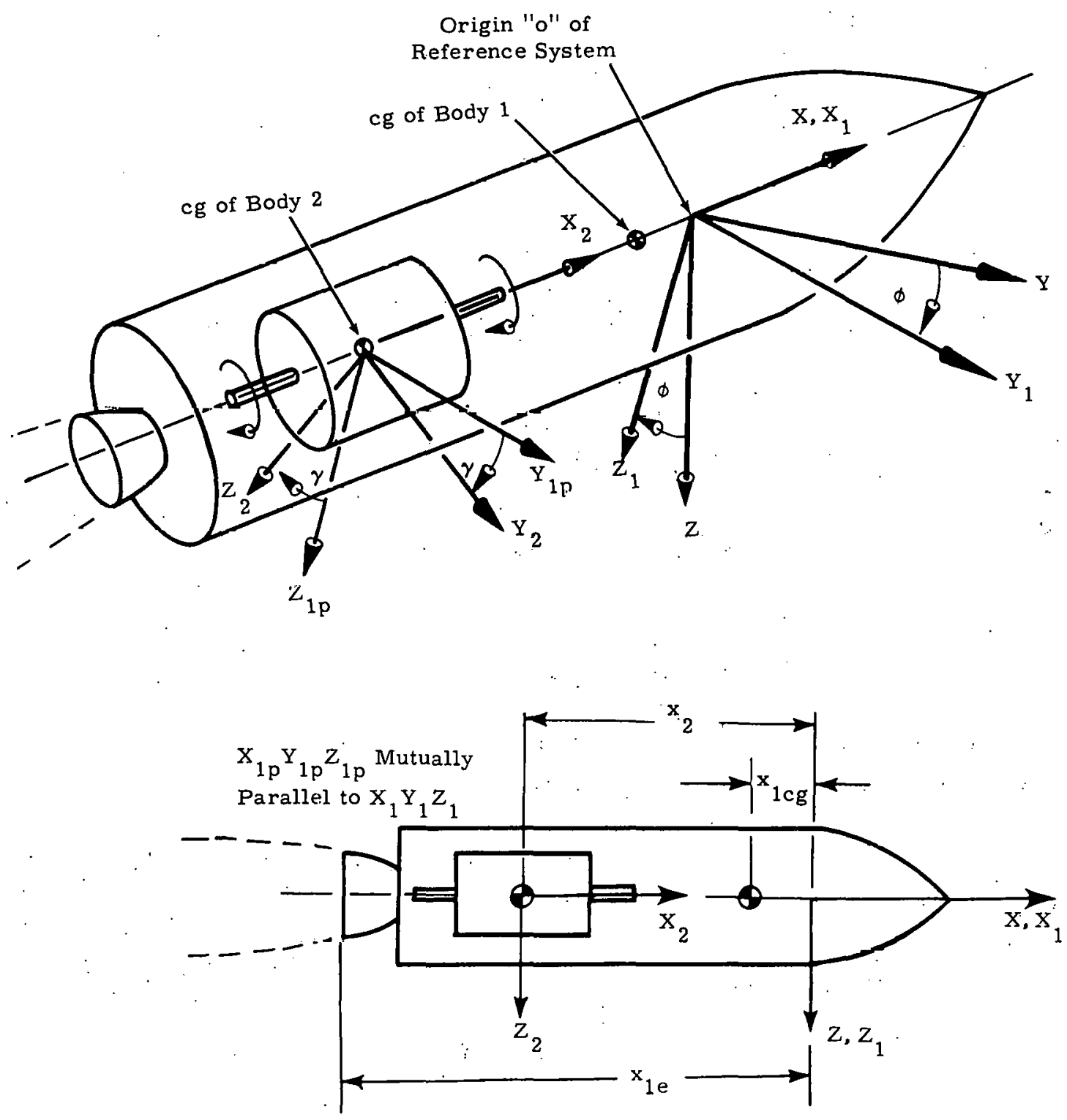

Figure 3. Spinning-Thrusting Body With Rotating Internal Component (Nonrolling Coordinates) 


$$
\begin{aligned}
& \overrightarrow{\mathrm{M}}_{2}=\dot{\vec{H}}_{2}+\vec{\Omega} \times \overrightarrow{\mathrm{H}}_{2}+\mathrm{m}_{2} \overrightarrow{\mathrm{r}}_{2} \times\left[\dot{\overrightarrow{\mathrm{V}}}+\vec{\Omega} \times \overrightarrow{\mathrm{V}}+\dot{\vec{\Omega}} \times \overrightarrow{\mathrm{r}}_{2}+\vec{\Omega} \times\left(\vec{\Omega} \times \overrightarrow{\mathrm{r}}_{2}\right)\right] \\
& \vec{F}=m[\dot{\vec{v}}+\vec{\Omega} \times \vec{v}]+\dot{m}_{1} \vec{v}+m \dot{\vec{\Omega}} \times \vec{r}_{c g}+m \vec{\Omega} \times\left(\vec{\Omega} \times \vec{r}_{c g}\right) \\
& +m_{1} \ddot{\vec{\rho}}_{1 \mathrm{cg}}+2 \mathrm{~m}_{1} \vec{\Omega} \times \dot{\vec{\rho}}_{1 \mathrm{cg}}+2 \dot{\mathrm{m}}_{1} \dot{\vec{\rho}}_{1 \mathrm{cg}}+\dot{\mathrm{m}}_{1} \vec{\Omega} \times\left(2 \vec{\Omega}_{1 \mathrm{cg}}-\vec{\rho}_{1 \mathrm{e}}\right) \\
& +\ddot{m}_{1}\left(\vec{p}_{1 \mathrm{cg}}-\vec{\rho}_{1 \mathrm{e}}\right) \\
& \overrightarrow{\mathrm{M}}_{\mathrm{o}}=\dot{\overrightarrow{\mathrm{H}}}_{1}+\overrightarrow{\mathrm{H}}_{2}, \vec{\Omega} \times\left(\overrightarrow{\mathrm{II}}_{1}+\overrightarrow{\mathrm{H}}_{2}\right)+\overrightarrow{\mathrm{r}}_{\mathrm{cg}} \times \overrightarrow{\mathrm{F}}-\overrightarrow{\mathrm{m}}_{\mathrm{cg}} \times\left[\overrightarrow{\vec{\Omega}} \times \vec{r}_{\mathrm{cg}}\right. \\
& \left.+\vec{\Omega} \times\left(\vec{\Omega} \times \vec{r}_{\mathrm{cg}}\right)\right]-m_{1} \vec{r}_{\mathrm{cg}} \times\left[\ddot{\vec{\rho}}_{1 \mathrm{cg}}+2 \vec{\Omega} \times \dot{\vec{\rho}}_{1 \mathrm{cg}}\right] \\
& +\mathrm{m}_{2} \overrightarrow{\mathrm{r}}_{2} \times\left[\dot{\vec{\Omega}} \times \overrightarrow{\mathrm{r}}_{2}+\vec{\Omega} \times\left(\vec{\Omega} \times \overrightarrow{\mathrm{r}}_{2}\right)\right]-\dot{\mathrm{m}}_{1} \overrightarrow{\mathrm{r}}_{\mathrm{cg}} \times\left[\overrightarrow{\mathrm{v}}+2 \dot{\vec{\rho}}_{1 \mathrm{cg}}\right. \\
& \left.+\vec{\Omega} \times\left(2 \vec{\rho}_{1 c g}-\vec{\rho}_{1 \mathrm{e}}\right)\right]-\dot{\mathrm{m}}_{1} \vec{\rho}_{1 \mathrm{e}} \times\left(\vec{\Omega} \times \vec{\rho}_{1 \mathrm{e}}\right)-\ddot{\mathrm{m}}_{1} \overrightarrow{\mathrm{r}}_{\mathrm{rg}} \times\left(\overrightarrow{\hat{\rho}}_{r g}-\vec{\rho}_{1 Q}\right)
\end{aligned}
$$

where $m=m_{1}+m_{2}, \dot{m}=\dot{m}_{1}$, and $\ddot{m}=\ddot{m}_{1}$. The force equation for Body 2 has been omitted since that body has only a single angular degree of freedom.

With the exception of $\overrightarrow{\mathrm{H}}_{1}$ and $\overrightarrow{\mathrm{H}}_{2}$, the vector quantities which appear in Eqs. (75) through (78) are defined in terms of their components relative to the $\mathrm{XYZ}$ nonrolling reference axis system as

$$
\begin{aligned}
& \vec{p}_{1 \mathrm{cg}}=\left(\mathrm{x}_{1 \mathrm{cg}}, 0,0\right) \\
& \vec{\rho}_{1 \mathrm{e}}=\left(\mathrm{x}_{1 \mathrm{e}}, 0,0\right) \quad \text { (constant) } \\
& \vec{r}_{2}=\left(x_{2}, 0,0\right) \quad \text { (Eonstaint) } \\
& \overrightarrow{\mathrm{M}}_{2}=\left(\mathrm{M}_{\mathrm{X}_{2}} \cdot \mathrm{M}_{\mathrm{Y}_{2}}-\mathrm{m}_{2} \mathrm{x}_{2} \mathrm{~g}_{\mathrm{Z}}, \mathrm{M}_{\mathrm{Z}_{2}}+\mathrm{m}_{2} \mathrm{x}_{2} \mathrm{~g}_{\mathrm{Y}}\right) \\
& \vec{F}=\left(F_{X}+m g_{X}, F_{Y}+m g_{Y}, F_{Z}+m g_{Z}\right) \\
& \vec{M}_{0}=\left[M_{X}, M_{Y}-\left(m_{1} x_{1 c y}+m_{2} x_{2}\right) g_{Z}, M_{Z}+\left(m_{1} x_{1 c g}+m_{2} x_{2}\right) g_{Y}\right]
\end{aligned}
$$




$$
\begin{aligned}
& \vec{v}=(\tilde{u}, \tilde{v}, \widetilde{w}) \\
& \vec{\Omega}=(\tilde{p}, \tilde{q}, \tilde{r})
\end{aligned}
$$

For this example, with the exceptions of $\mathrm{F}_{\mathrm{X}}$ and $\mathrm{M}_{\mathrm{X}_{2}}$, the nongravitational forces and moments ( $F_{Y}, F_{Z}, M_{X}$, etc.) appearing in Eqs. (82) through (84) result entirely from aerodynamic effects. The axial force $F_{X}$ contains thrust in addition to aerodynamic force. Since Body 2 is internal, the moment $\mathrm{M}_{\mathrm{X}}$, is composed entirely of moments input to Body 2 by some action rela-. tive to Body 1; E.g., a motor attached to Body 1 and applying a torque to Body 2, These interaction moments do not appear in $\mathrm{M}_{\mathrm{X}}$ because of the moments of equivalent magnitude but opposite sign that they induce in the two-body system.

The inertially referenced angular velocities of the bodies resolved into components along their respective body-fixed coordinate directions are given as

$$
\hat{\omega}_{j}=\left(p_{j}, q_{j}, r_{j}\right) \quad(j=1,2) .
$$

These components and those of $\vec{\Omega}[\mathrm{Eq} .(86)]$ are related as follows:

$$
\begin{aligned}
& \tilde{p}=p_{1}-\dot{\phi}=p_{2}-(\dot{\phi}+\dot{\gamma}) \\
& \tilde{q}=q_{1} \cos \phi-r_{1} \sin \phi=q_{2} \cos (\phi+\gamma)-r_{2} \sin (\phi+\gamma) \\
& \tilde{r}=q_{1} \sin \phi+r_{1} \cos \phi=q_{2} \sin (\phi+\gamma)+r_{2} \cos (\phi+\gamma)
\end{aligned}
$$

Because the rotational inertial properties of these bodies will be measured relative to the $\mathrm{X}_{j} \mathrm{Y}_{j} \dot{Z}_{j}(\mathrm{j}=1,2)$ body-fixed axes, the apparent moment of momentum vectors for the bodies will initially be defined relative to these same axes; $i_{\text {. }}$, , as $\hat{H}_{j}(j=1,2)$. Using Eqs. (61), (62), and (87), assuming a symmetric distribution relative to the $x_{1}$ and $x_{2}$ axes of the rigid and/or moving mass, and neglecting $\hat{\mathscr{Z}}_{1}\left(\hat{\mathscr{H}}_{2}=0\right.$, Body 2 is rigid $)$

$$
\hat{H}_{j}=\left(I_{X} p_{j}, I_{j} q_{j}, I_{j} r_{j}\right) \quad(j=1,2)
$$

Substituting Eq. (88) together with the respective vector transformation matrices [see Eq. (54) for matrix form] into Eq. (57) and writing the lateral rates in terms of those of the XYZ reference system, the apparent moment of momentum vectors become

$$
\vec{H}_{j}=\left(I_{X}{ }_{j} p_{j}, I_{j} \widetilde{q}, I_{j} \widetilde{r^{\prime}}\right) . \quad(j=1,2) .
$$


Combining Eqs. (89) together with Eqs. (75) through (86), the vector equations of motion can be expanded into the following scalar forms:

$$
\begin{aligned}
& x_{c g}-\left(\frac{m_{1}}{m}\right) x_{1 c g}+\left(\frac{m_{2}}{m}\right) x_{2} \\
& \mathrm{M}_{\mathrm{X}_{2}}=\mathrm{I}_{\mathrm{X}_{2}}\left(\dot{\mathrm{p}}_{1}+\ddot{\gamma}\right)=\mathrm{I}_{2} \dot{\mathrm{p}}_{2} \\
& F_{X}+m g_{X}=m(\dot{\widetilde{u}}+\tilde{q w}-\tilde{r} \tilde{v})-m x_{c g}\left(\tilde{q}^{2}+\tilde{r}^{2}\right)+m_{1} \ddot{x}_{1 c g} \\
& +\dot{\mathrm{m}}_{1}\left(\tilde{\mathrm{u}}+2 \dot{\mathrm{x}}_{1 \mathrm{n} g}\right)+\ddot{\mathrm{m}}_{1}\left(\mathrm{x}_{1, \cdot \mathrm{g}}-\mathrm{x}_{1 \mathrm{e}}\right) \\
& \left.F_{Y}+m g_{Y}=m\left[\dot{\tilde{v}}+\tilde{r}\left(\tilde{u}+2\left(\frac{m_{1}}{m}\right) \dot{x}_{1 c g}\right)-\tilde{p} \tilde{w}\right]+m x_{c g} \dot{(\tilde{r}}+\tilde{p} \widetilde{q}\right) \\
& +\dot{m}_{1}\left(\tilde{v}+x_{1 c g} \tilde{r}\right)+\dot{m}_{1}\left(x_{1 c g}-x_{1 e}\right) \tilde{r} \\
& F_{Z}+m g_{Z}=m\left[\dot{\tilde{w}}+\tilde{p} \tilde{v}-\tilde{q}\left(\tilde{u}+2\left(\frac{m_{1}}{m}\right) \dot{x}_{1 c g}\right)\right]+m x_{c g}(\tilde{p r}-\dot{\widetilde{q}}) \\
& +\dot{m}_{1}\left(\tilde{w}-x_{1 c g} \tilde{q}\right)-\dot{m}_{1}\left(x_{1 c g}-x_{1 e}\right) \tilde{q} \\
& M_{X}-M_{X_{2}}-I_{X_{1}} \dot{P}_{1}+\dot{I}_{X_{1}} p_{1} \\
& \mathrm{M}_{\mathrm{Y}}=\left[\left(\mathrm{I}_{1}+\mathrm{I}_{2}+\mathrm{m}_{2} \mathrm{x}_{2}^{2}\right)-\mathrm{mx}_{\mathrm{cg}}^{2}\right](\dot{\tilde{\mathrm{q}}}-\tilde{\mathrm{pr}})+\left[\left(\mathrm{L}_{1}+\mathrm{I}_{\mathrm{X}_{2}}\right) \mathrm{p}_{1}+\mathrm{I}_{\mathrm{X}_{2}} \dot{\mathrm{\gamma}}\right] \tilde{\mathrm{r}} \\
& \text { I }\left\{\left[\dot{\mathrm{I}}_{1}-2 \mathrm{~m}_{1} \mathrm{x}_{\mathrm{cg}} \dot{\mathrm{x}}_{1 \mathrm{cg}}-\dot{\mathrm{m}}_{1} \mathrm{x}_{\mathrm{cg}} \mathrm{x}_{1 \mathrm{cg}}\right]-\dot{\mathrm{m}}_{1}\left[\mathrm{x}_{\mathrm{cg}}\left(\mathrm{x}_{1 \mathrm{gg}}-\mathrm{x}_{1 \mathrm{e}}\right)+\mathrm{x}_{1 \mathrm{e}}^{2}\right]\right\} \tilde{\mathrm{q}} \\
& -x_{c g}\left(F_{z}-\dot{m}_{1} \tilde{w}\right)
\end{aligned}
$$




$$
\begin{aligned}
M_{Z}= & {\left[\left(I_{1}+I_{2}+m_{2} x_{2}^{2}\right)-m x_{c g}^{2}\right](\dot{\tilde{r}}+\tilde{p q})-\left[\left(L_{x_{1}}+I_{x_{2}}\right) \dot{p}_{1}+I_{x_{2}} \dot{\gamma}\right] \tilde{q} } \\
& +\left\{\left[\dot{I}_{1}-2 m_{1} x_{c g} \dot{x}_{1 c g}-\dot{m}_{1} \dot{x}_{c g} x_{1 c g}\right]-\dot{m}_{1}\left[x_{c g}\left(x_{1 c g}-x_{1 e}\right)+x_{1 e}^{2}\right]\right\} \tilde{r} \\
& +x_{c g}\left(F_{Y}-\dot{m}_{1} \tilde{v}\right)
\end{aligned}
$$

The mass variation induced effects of thrust, rate of change of moment of inertia, variation of cg location, and jet damping are all included in Eqs. (90) through (97). These equations can be used to investigate the motion of spinning vehicles having rotating internal flywheels, stable platforms, etc., with or without the effects of mass variation being present.

\section{Flexible Joint}

The-multiple body system used for this example (Figure 4 ) consists of two spinning bodies connected by a flexible joint (spring). Motion of the aft variable mass (thrusting) body (Body 2) relative to the rigid forebody (Body 1) is constrained to small rotations about a pivot point located at the base of Body 1 on its axis of symmetry. The $X_{1} Y_{1} Z_{1}$ body-fixed coordinates (Body 1 , Figure 4) and the $\mathrm{XYZ}$ reference system are coincident with their collnear $\mathrm{X}_{\text {and }} \mathrm{X}_{1}$ axes directed forward along the axis of symmetry of Body 1 and their origins are fixed at the $\mathrm{cg}$ of the body $\left(\hat{r}_{1}=\hat{\rho}_{1 \mathrm{cg}}=0\right)$. The $\mathrm{X}_{2} \mathrm{Y}_{2} \mathrm{Z}_{2}$ axis system is fixed in Body 2 with its origin at the pivot point $\left\langle\hat{r}_{2}=x_{2}, 0,0\right)$ and its $x_{2}$ axis directed forward along the axis of symmetry of Body 2 . Note that the $\mathrm{cg}$ of Body 2, which is located away from the origin of the $\mathrm{X}_{2} \mathrm{Y}_{2} \mathrm{Z}_{2}$ axes, is also assumed to lie on the Body 2 axis of symmetry ( $\left.\hat{\rho}_{2 \mathrm{cg}}=\mathrm{X}_{2 \mathrm{cg}}, 0,0\right)$. As shown in Figure 4 , the angular position of $X_{2} Y_{2} Z_{2}$ relative to $X_{1} Y_{1} Z_{1}\left(X_{1 p} Y_{1 p} Z_{1 p}\right.$ is mutually parallel with $\left.X_{1} Y_{1} Z_{1}\right)$, i. e., the angular position of Body 2 relative to Body 1, is specified by the Euler rotation angles $\Psi, \theta$ in a yaw-pitch sequence.

A set of vector equations which describe the motion of this system of bodies can be obtained. from Eqs. (52), (68), and (71) through (74) as

$$
\begin{aligned}
& \vec{m}_{\mathrm{cg}}=\mathrm{m}_{2}\left(\overrightarrow{\mathrm{r}}_{2}+{\overrightarrow{\beta_{2 c g}}}_{2}\right) \\
& \overrightarrow{\mathrm{F}}=\mathrm{m}\left[\dot{\vec{v}}+\vec{\Omega} \times \overrightarrow{\mathrm{v}}+\dot{\vec{\Omega}} \times \overrightarrow{\mathrm{r}}_{\mathrm{cg}}+\vec{\Omega} \times\left(\vec{\Omega}_{\mathrm{r}} \times \overrightarrow{\mathrm{r}}_{\mathrm{cg}}\right)\right]+\mathrm{m}_{2}\left(\ddot{\vec{\rho}}_{2 \mathrm{cg}}+2 \vec{\Omega} \times \dot{\vec{\rho}}_{2 \mathrm{cg}}\right) \\
& \quad+\dot{\mathrm{m}}_{2}\left[\overrightarrow{\mathrm{V}}+2 \dot{\vec{\rho}}_{2 \mathrm{cg}}-\dot{\vec{\rho}}_{2 \mathrm{e}}+\vec{\Omega} \times\left(\overrightarrow{\mathrm{r}}_{2}+2 \vec{\rho}_{2 \mathrm{cg}}-\vec{\rho}_{2 \mathrm{e}}\right)\right]+\ddot{\mathrm{m}}_{2}\left(\vec{\rho}_{2 c g}-\vec{\rho}_{2 \mathrm{e}}\right)
\end{aligned}
$$




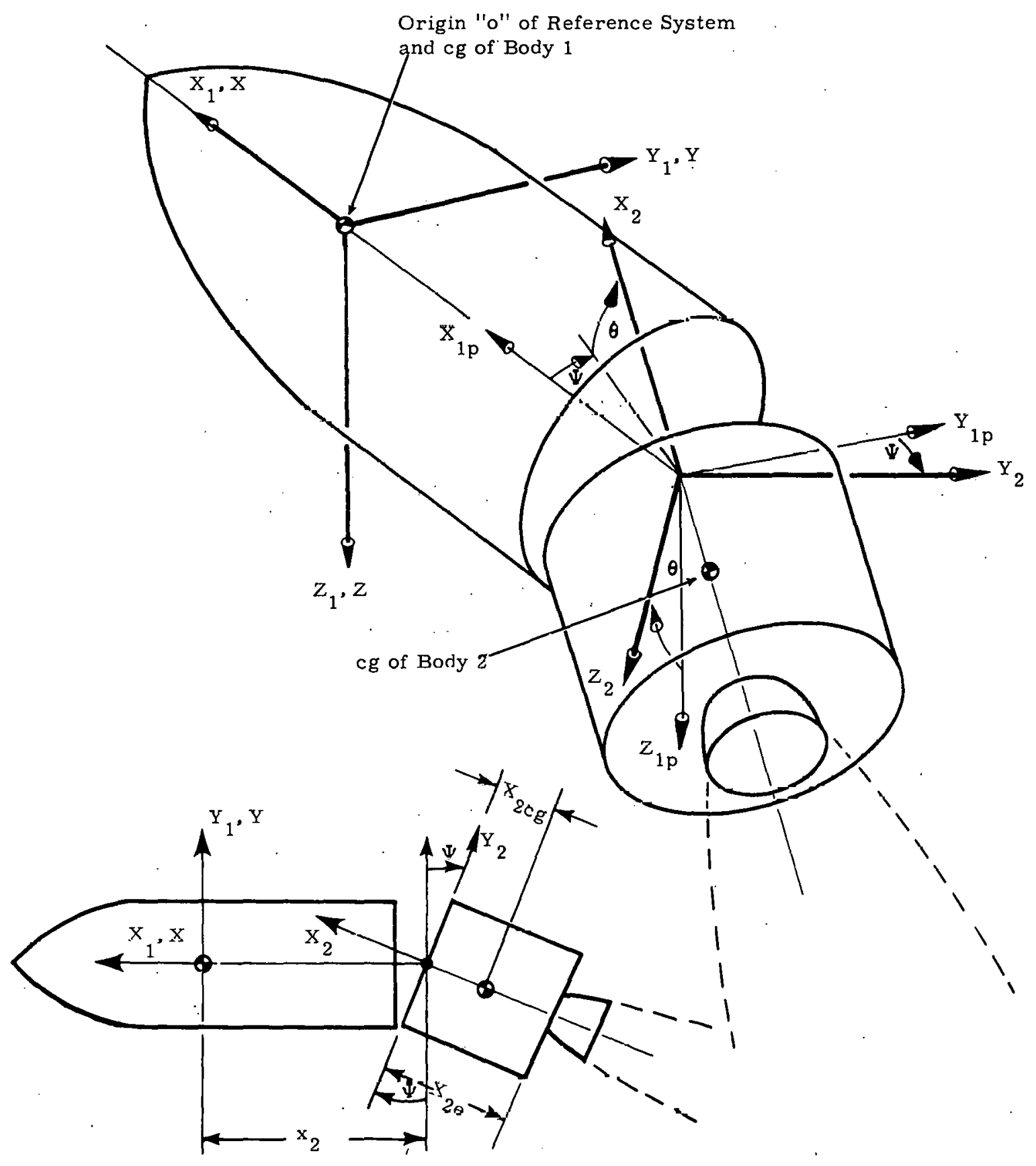

Figure 4. Spinning-Thrusting Body with Flexible Joint 


$$
\begin{aligned}
& \vec{M}_{0}=\dot{\vec{H}}_{1}+\dot{\vec{H}}_{2}+\vec{R} \times\left(\vec{H}_{1}+\vec{H}_{2}\right)+\left(\vec{r}_{2}+\vec{\rho}_{2 c g}\right) \times\left[\vec{F}-m_{1}(\dot{\vec{v}}+\vec{R} \times \vec{v})\right] \\
& -\mathrm{m}_{2} \vec{\rho}_{2 \mathrm{cg}} \times\left[\ddot{\vec{\rho}}_{2 \mathrm{cg}}+\dot{\vec{\Omega}} \times \vec{\rho}_{2 \mathrm{cg}}+2 \vec{\Omega} \times \dot{\vec{p}}_{2 \mathrm{cg}}+\vec{\Omega} \times\left(\vec{\Omega} \times \vec{\rho}_{2 \mathrm{cg}}\right)\right] \\
& -\dot{\mathrm{m}}_{2} \vec{\rho}_{2 \mathrm{cg}} \times\left[\overrightarrow{\mathrm{v}}+2 \dot{\vec{\rho}}_{2 \mathrm{cg}}-\vec{\rho}_{2 \mathrm{e}}+\Omega \times\left(\overrightarrow{\mathrm{r}}_{2}+2 \overrightarrow{\mathrm{R}}_{2 \mathrm{cg}}-\vec{\rho}_{2 \mathrm{e}}\right)\right] \\
& -\dot{\mathrm{m}}_{2} \vec{\rho}_{2 \mathrm{e}} \times\left[\overrightarrow{\vec{\rho}}_{2 \mathrm{e}}+\left(\vec{\Omega} \times \overrightarrow{\hat{p}}_{2 \mathrm{e}}\right)\right]+\ddot{\mathrm{m}}_{2} \vec{\rho}_{2 \mathrm{cg}} \times \vec{\rho}_{2 \mathrm{e}}
\end{aligned}
$$$$
\overrightarrow{\mathrm{M}}_{0}-\overrightarrow{\mathrm{M}}_{2}=\dot{\overrightarrow{\mathrm{H}}}_{1}+\vec{\Omega} \times \overrightarrow{\mathrm{H}}_{1}
$$

where $\mathrm{m}=\mathrm{m}_{1}+\mathrm{m}_{2}, \dot{\mathrm{m}}=\dot{\mathrm{m}}_{2}$, and $\ddot{\mathrm{m}}=\ddot{\mathrm{m}}_{2}$. To minimize the number of terms in the above vector equations, the moment equation for Body 1 [ Eq. (101)] has been used in place of the Body 2 momont equation. Both moment equations contain the spring interaction moment.

Certain vector quantities used to characterize this problem (those that do not require derivetion or transformation) can be written directly in terms of their components relative to the various coordinate systems. These are given as

$$
\begin{aligned}
& \hat{\rho}_{2 e}=\left(x_{2 e}, 0,0\right) . \quad \text { (constant) } \\
& \hat{\rho}_{2 \mathrm{cg}}=\left(\mathrm{x}_{2 \mathrm{cg}}, 0,0\right) . \quad \text { (constant) } \\
& \hat{\mathrm{r}}_{2}=\left(\mathrm{x}_{2}, 0,0\right) \quad \text { (constant) } \\
& \vec{\Omega}=\dot{\omega}_{1}=(p, q, r) \\
& \hat{\omega}_{2}=\left(\dot{p}_{2}, q_{2}, r_{2}\right) \\
& \overrightarrow{\mathrm{v}}=(u, v, w) \\
& \vec{F}=\left(F_{X}+m_{X}, F_{Y}+m g_{Y}, F_{Z}+m g_{Z}\right) \\
& \vec{M}_{0}=\left\{\dot{M}_{X}+m_{2}\left(y_{2 c g} g_{Z}-z_{2 c g} g_{Y}\right) \cdot M_{Y}+m_{2}\left[z_{2 c g} g_{X}-\left(x_{2}+x_{2 c g}\right) g_{Z}\right] \cdot M_{Z}\right. \\
& \left.+m_{2}\left[\left(x_{2}+x_{2 c g}\right) g_{Y}-y_{2 c g} g_{X}\right]\right\}
\end{aligned}
$$

(104)

(10்)

35 


$$
\begin{aligned}
\vec{M}_{2}= & \left\{M_{X_{2}}+m_{2}\left(y_{2 c g} g_{Z}-z_{2 c g} g_{Y}\right) \cdot M_{Y_{2}}-(K \theta+c \dot{\theta})+m_{2}\left[z_{2 c g} g_{X}\right.\right. \\
& \left.\left.-\left(x_{2}+x_{2 c g}\right) g_{Z}\right) \cdot M_{Z_{2}}-(K \Psi+C \dot{\Psi})+m_{2}\left[\left(x_{2}+x_{2 c g}\right) g_{Y}-y_{2 c g} g_{X}\right]\right\} .
\end{aligned}
$$

The terms $\mathrm{x}_{2 \mathrm{cg}}, \mathrm{y}_{2 \mathrm{cg}}$, and $\mathrm{z}_{2 \mathrm{cg}}$ used in Eqs. (109) and (110) are components of $\vec{p}_{2 \mathrm{cg}}$ which will be established after transforming $\hat{\rho}_{2 \mathrm{cg}}$ [Eq. (103)]. Note the presence of the interaction moments $-(K \theta+C \dot{\theta})$ and $-(K \Psi+C \dot{\Psi})$ in Eq. (110). The forces and moments $F_{X}, F_{Y}, F_{Z}, M_{Y}$, and $M_{Z}$ in Eqs. (108) and (109) contain contributions from aerodynamic reaction and thrust, while $M_{X}$, $\mathrm{M}_{\mathrm{X}_{2}}, \mathrm{M}_{\mathrm{Y}_{2}}$, and $\mathrm{M}_{\mathrm{Z}_{2}}$ of Eqs. (109) and (110) result only from aerodynamic reaction.

Using Eqs. (61), (105), and (106), assuming a symmetrical distribution of the rigid and/or moving mass relative to the body-fixed axes, and neglecting $\hat{\mathscr{Z}}_{2}\left(\hat{\mathscr{Z}}_{1}=0\right.$, Body 1 is rigid), the apparent moment of momentum vectors for Bodies 1 and 2 can be written as

$$
\begin{aligned}
& \overrightarrow{\mathrm{H}}_{1}=\hat{\mathrm{H}}_{1}=\mathrm{I}_{\mathrm{X}_{1}} \mathrm{p}, \mathrm{I}_{1} \mathrm{q}, \mathrm{I}_{1} \mathrm{r} \\
& \hat{\mathrm{H}}_{2}=\mathrm{I}_{\mathrm{X}_{2}} \mathrm{p}_{2}, \mathrm{I}_{2} \mathrm{q}_{2}, \mathrm{I}_{2} \mathrm{r}_{2}
\end{aligned}
$$

where $\mathrm{I}_{\mathrm{X}_{1}}, \mathrm{I}_{1}$ are constants, $\mathrm{I}_{\mathrm{X}_{2}}, \mathrm{I}_{2}$ are variables, and

$$
\begin{aligned}
& \mathrm{p}_{2}=p \cos \theta \cos \Psi+q \cos \theta \sin \Psi-(r+\dot{\Psi}) \sin \theta \\
& q_{2}=(q \cos \Psi+\dot{\theta})-p \sin \Psi \\
& r_{2}=(r+\dot{\Psi}) \cos \theta+p \sin \theta \cos \Psi+q \sin \theta \sin \Psi .
\end{aligned}
$$

To complete the definitions of the vector quantities that appear in Eqs. (98) through (101) in terms of their components relative to the XYZ reference system. it is nerpssary to transform tho components of $\hat{\rho}_{2 \mathrm{e}}, \hat{\rho}_{2 \mathrm{cg}}$, and $\hat{\mathrm{H}}_{2}$. Substituting Eqs. (102), (103), and (112) together with the vector transformation matrix [see Eq. (54) for matrix form] into Eqs. (59), (58), and (57), insinilivivly,

$$
\begin{aligned}
& \vec{\rho}_{2 \mathrm{e}}=\left(\mathrm{x}_{2 \mathrm{e}} \cos \theta \cos \Psi, \mathrm{X}_{2 \mathrm{e}} \cos \theta \sin \Psi,-\mathrm{x}_{2 \mathrm{e}} \sin \theta\right) \\
& \vec{\rho}_{2 \mathrm{cg}}=\left(\mathrm{x}_{2 \mathrm{cg}}, \mathrm{y}_{2 c g^{\prime}} \mathrm{z}_{2 \mathrm{cg}}\right)=\left(\mathrm{x}_{2 \mathrm{cg}} \cos \theta \cos \Psi, \mathrm{x}_{2 \mathrm{cg}} \cos \theta \sin \Psi,-\mathrm{x}_{2 \mathrm{cg}} \sin \theta\right)(114 \\
& \overrightarrow{\mathrm{H}}_{2}=\left(\mathrm{H}_{2}, \mathrm{H}_{\mathrm{Y}_{2}}, \mathrm{H}_{\mathrm{Z}_{2}}\right)
\end{aligned}
$$


where

$$
\begin{aligned}
& \mathrm{H}_{\mathrm{X}_{2}}=\left(\mathrm{I}_{2} \cos ^{2} \theta+\mathrm{I}_{2} \sin ^{2} \theta\right)(\mathrm{p} \cos \Psi+\mathrm{q} \sin \Psi) \cos \theta \\
& +I_{2}[p \sin \Psi-(q \cos \Psi+\dot{\theta})] \sin \Psi \\
& +\left(I_{2}-I_{X_{2}}\right)(r+\dot{\Psi}) \sin \theta \cos \theta \cos \Psi \\
& \left.\dot{H}_{Y_{2}}=I_{2} \mid(q \cos \Psi+\dot{\theta})-p \sin \Psi\right] \cos \Psi+\left(I_{2}-I_{X_{2}}\right)(r+\dot{\Psi}) \sin \theta \cos \theta \sin \Psi \\
& +\left(I_{X} \cos ^{2} \theta+I_{2} \sin ^{2} \theta\right)(q \sin \Psi+p \cos \Psi) \sin \Psi \\
& \mathrm{H}_{Z_{2}}=\left(\mathrm{I}_{\mathrm{X}_{2}} \sin ^{2} \theta+\mathrm{I}_{2} \cos ^{2} \theta\right)(\mathrm{r}+\dot{\Psi})+\left(\mathrm{I}_{2}-\mathrm{I}_{\mathrm{X}_{2}}\right)(p \cos \Psi+q \sin \Psi) \sin \theta \cos \theta .
\end{aligned}
$$

Note that since $X_{2 e}$ and $X_{2 c g}$ were assumed constant [Eqs, (102) and (103)], $\vec{\rho}_{2 e}$ and $\vec{\rho}_{2 c g}$ [Eqs. (113) and (114)] are variables only due to the presence of $\Psi$ and $\theta$. A constant $X_{2 e}$ realistically fits this problem. Constant $\mathrm{X}_{2 \mathrm{cg}}$ was introduced principally to simplify the final form of the equations; however, there are motors, like radial burning rockets, that have characteristics which fit this assumption. The characteristics of these radial burning rockets could also satisfy the previous assumption concerning symmetric distribution of the rigid and moving mass relative to axes of symmetry.

A completely general expansion of Eqs, (98) through (101) to scalar form would result in a set of equations with an extremely large number of terms involving products of trigonometric functions. Because the angular displacements $\Psi$ and $\theta$ are small, $\cos \Psi \approx \cos \theta \approx 1, \sin \Psi \approx \Psi$, and $\sin \theta \approx i \theta$. In order to further simplify the final form of these equations, which would otherwise include many terms having negligible effect on the motion, it was assumed that terms involving products of $\Psi$ and/or $\theta$ could be ignored; however, all indicated differentiation in Eqs. (99) . through (101) was completed prior to applying this assumption.

Using the approximations for the trigonometric functions and neglecting small terms in the combination and expansion of Eqs. (98) through (115), the scalar differential equations of motion for the two-body system shown in Figure 4 can be written as: 


$$
\begin{aligned}
F_{X}+m_{X}= & m(\dot{q}+q w-r v)+\dot{m}_{2} u-m_{2} x_{2 c g}\{[(\dot{r}+\ddot{\Psi})-q p] \Psi \\
& +\left[(\dot{q}+\ddot{\theta})+r p \mid \theta+(q+\dot{\theta})^{2}+(r+\dot{\Psi})^{2}\right\}-m_{2} x_{2}\left(q^{2}+r^{2}\right) \\
& -\dot{m}_{2}\left(2 X_{2 c g}-x_{2 e}\right)[(q+\dot{\theta}) \theta+(r+\dot{\Psi}) \Psi]+\ddot{m}_{2}\left(x_{2 c g}-x_{2 e}\right) \\
F_{Y}+m_{Y}= & m(\dot{v}+r u-p w)+\dot{m}_{2}\left(v+x_{2} r\right) \\
& +m_{2} x_{2 c g}\left\{(\dot{r}+\ddot{\Psi})-\left[p^{2}+\left(r+\dot{\Psi}^{2}+(\dot{\theta})^{2}\right] \Psi-\mid(r q-p)\right.\right. \\
& +2 \dot{\theta}(r+\dot{\Psi})] \theta+(u+2 \dot{\theta}) p\}+m_{2} x_{2}(\dot{r}+p q) \\
& \left.+\dot{m}_{2}\left(2 X_{2 c g}-x_{2 e}\right) \mid(r+\dot{\Psi})+p \theta\right]+\ddot{m}_{2}\left(x_{2 c g}-x_{2 e}\right) \Psi
\end{aligned}
$$

(117)

$$
\begin{aligned}
& F_{z}+m g_{z}=m(\dot{w}+p v-q u)+\dot{m}_{2}\left(w-x_{2} q\right) \\
& -\mathrm{m}_{2} \mathrm{x}_{2 c \mathrm{~g}}\left\{(\dot{\mathrm{q}}+\ddot{\theta})-\left[\mathrm{p}^{2}+(\mathrm{q}+\dot{\theta})^{2}\right] \theta-[(\mathrm{qr}+\dot{\mathrm{p}})+2 \mathrm{q} \dot{\Psi}] \Psi\right. \\
& -(r+2 \dot{\Psi}) p\}+m_{2} x_{2}(p r-\dot{q})+\dot{m}_{2}\left(2 x_{2 v g}-x_{2 e}\right)[p \Psi-(q+\dot{q})] \\
& -\ddot{\mathrm{m}}_{2}\left(\mathrm{x}_{2 \mathrm{eg}}-\mathrm{x}_{2 \mathrm{e}}\right) \theta \\
& \mathrm{M}_{\mathrm{X}}=\left(\mathrm{I}_{\mathrm{X}_{1}}+\mathrm{I}_{\mathrm{X}_{2}}\right) \dot{\mathrm{p}}+\mathrm{I}_{\mathrm{X}_{2}}\{[\mathrm{q} \dot{\Psi}-(\mathrm{r}+\dot{\Psi}) \dot{\theta}+\dot{\mathrm{q}} \Psi-(\dot{\mathrm{r}}+\ddot{\Psi}) \theta]+[(\mathrm{q}+2 \dot{\theta}) \theta \\
& +(\mathrm{r}+2 \dot{\Psi}) \Psi] p\}+\left(\mathrm{I}_{2}-\mathrm{m}_{2} \mathrm{x}_{2 \mathrm{cg}}^{2}\right)\{[(\dot{\mathrm{r}}+\ddot{\Psi}) \theta-(\dot{\mathrm{q}}+\ddot{\theta}) \Psi]+[(\mathrm{q}+2 \dot{\theta}) \theta \\
& +(r+2 \dot{\Psi}) \Psi] p\}-\left[\dot{\mathrm{I}}_{2}-\dot{\mathrm{m}}_{2}\left(\mathrm{x}_{2 \mathrm{cg}}^{2}+\mathrm{x}_{2 \mathrm{cg}}\left(\mathrm{x}_{2 \mathrm{cg}}-\mathrm{x}_{2 \mathrm{e}}\right)+\mathrm{x}_{2 \mathrm{e}}^{2}\right)\right][(\mathrm{q}+\dot{\theta}) \Psi
\end{aligned}
$$

38 


$$
\begin{aligned}
& -(r+\dot{\Psi}) \theta]+\dot{L}_{X_{2}}[q \Psi-(r+\dot{\Psi}) \theta]-\dot{m}_{2} x_{2 c g}\left[\left(w+x_{2} q\right) \Psi+\left(v-x_{2} r\right) \theta\right] \\
& +X_{2 c g}\left\{\left[F_{Z}-m_{1}\left(\dot{w}+p v-q u-g_{Z}\right)\right] \Psi+\left[F_{Y}-m_{1}\left(\dot{v}+r u-p w-g_{Y}\right)\right] \theta\right\} \\
& M_{Y}=I_{1} \dot{q}+\left[I_{2}-m_{2} x_{2 c g}^{2}\right]\left\{(\dot{q}+\ddot{\theta})-2 \dot{\Psi}(p+q \Psi)-\left[p^{2}-r(r+\dot{\Psi})\right] \theta\right. \\
& -(p+q r) \Psi\}+\left[\left(I_{X_{1}}+I_{X_{2}}\right)-\left(I_{1}+I_{2}\right)+m_{2} x_{2 c g}^{2}\right] p r+I_{X_{2}}\{p \dot{\Psi} \\
& \left.+[(\dot{p}+q r)-\dot{\theta}(r+\dot{\Psi})] \Psi+\left[p^{2}-r(r+\dot{\Psi})\right] \theta\right\}-m_{2} x_{2 c g}^{2} \dot{\Psi}(r+\dot{\Psi}) \theta \\
& +\dot{\mathrm{I}}_{\mathrm{x}_{2}} \mathrm{p \Psi}+\left[\dot{\mathrm{I}}_{2}-\dot{\mathrm{m}}_{2}\left(\mathrm{x}_{2 c \mathrm{~g}}^{2}+\mathrm{x}_{2 \mathrm{cg}}\left(\mathrm{x}_{2 c \mathrm{~g}}-\dot{x}_{2 \mathrm{e}}\right)+\dot{x}_{2 \mathrm{e}}^{2}\right)\right][(q+\ddot{\theta})-p \Psi] \\
& +\dot{m}_{2} x_{2 c g}\left(w+u \theta-x_{2} q\right)-\left(x_{2}+x_{2 c g}\right)\left[F_{Z}-m_{1}\left(\dot{w}+p v-q u-g_{Z}\right)\right] \\
& -x_{2 c g} \cdot\left[F_{X}-m_{1}\left(\dot{u}+q w-r v-g_{X}\right)\right] \theta \\
& M_{Z}=I_{Z_{1}} \dot{r}+\left[I_{2}-m_{2} X_{2 c g}^{2}\right]\{(\dot{r}+\ddot{\Psi})+2 \dot{\theta}[(p+q \Psi)-(r+\dot{\Psi}) \theta] \\
& \left.+(\dot{p}-\mathrm{rq}) \theta-\left(\mathrm{p}^{2}-\mathrm{q}^{2}\right) \dot{\Psi}\right\}+\left[\left(\mathrm{I}_{1}+\mathrm{I}_{2}\right)-\left(\mathrm{I}_{\mathrm{x}_{1}}+\mathrm{I}_{\mathrm{X}_{2}}\right)-\mathrm{m}_{2} \mathrm{x}_{2 \mathrm{cg}}^{2}\right] \mathrm{pq} \\
& +I_{X_{2}}\left\{\left[p^{2}-q(q+\dot{\theta})\right] \Psi-p \dot{\theta}+[(q r-\dot{p})+2 \dot{\theta}(r+\dot{\psi})] \theta\right\} \\
& -\mathrm{t}_{\mathrm{x}_{2}} \mathrm{p} \theta+\left[\dot{\mathrm{i}}_{2}-\dot{\mathrm{m}}_{2}\left(\mathrm{x}_{2 \mathrm{cg}}^{2}+\mathrm{x}_{2 \mathrm{cg}}\left(\mathrm{x}_{2 \mathrm{cg}}-\mathrm{x}_{2 \mathrm{e}}\right)+\mathrm{x}_{2 \mathrm{e}}^{2}\right)\right][(\mathrm{r}+\dot{\mathrm{v}})+\mathrm{p \theta}] \\
& -\dot{m}_{2} x_{2 c g}\left(v-u \theta+x_{2} r\right)-x_{2 c g}\left[F_{X}-m_{1}\left(\dot{u}+q w-r v-g_{X}\right)\right] \Psi \\
& +\left(x_{2}+x_{2 c g}\right)\left[F_{Y}-m_{1}\left(v+r u-p w-g_{Y}\right)\right] \\
& \mathrm{M}_{\mathrm{Y}}-\mathrm{M}_{\mathrm{Y}_{2}}+(\mathrm{K} \theta+\dot{\mathrm{\theta}})=\mathrm{I}_{1} \dot{\mathrm{q}}+\left(\mathrm{I}_{\mathrm{X}_{1}}-\mathrm{I}_{1}\right) \mathrm{pr} \\
& M_{Z}-M_{Z_{2}}+(K \Psi+C \dot{\Psi})=I_{1} \dot{r}+\left(I_{1}-I_{X_{1}}\right) p q
\end{aligned}
$$

39 
Equations (116) through (123) are useful for studying the effects of joint stiffness and damping on both the relative motion and overall motion of a spinning two-body system with or without the effects of mass variation being present.

\section{Conclusion}

A general vector differential equation set has been developed to describe the motion of a sys tem of $j(j=1,2, \ldots n)$ rotating-translating variable-mass variable configuration bodies relative to a rotating reference frame. These equations include: (1) a complete treatment of the effects of varying mass; (2) complete flexibility in the placement and motion of the reference coordinate frame within the system of bodies (nonrolling reference coordinates are one of many types that can be implemented); (3) complete flexibility in the placement of the body-fixed axes within each body of the system (mass asymmetry can be introduced), and (4), the provision for relative translation and rotation to exist between the reference coordinates and each body of the system as well. as between the respective bodies. Through the use of simple restraints, these general equations are easily reduced to the governing equations for the motions of many dynamic systems of interest. Two examples are given to illustrate their flexibility and usefulness.

\section{References}

1. D. T. Greenwood, Principles of Dynamics, Prentice-Hall Incorporated, Englewood Cliffs, New Jersey, 1965.

2. W. T. Thomson, Introduction to Space Dynamics, New York, London: John Wiley and Sons, Incorporated, 1961 .

3. R. C. Brown, R. V. Brulle, A. L. Combs. and G. D. Giffin, Six-Degree-of-Freedom FlightPath Study Generalized Computer Program, Part I-Problem Formulation, Air Force Flight Dynamics Laboratory, Wright-Patterson Air Force Base, Ohio: RTD-TDR-64-1 Part 1, Volume 1, October 1964.

4. A. E. Hodapp, Jr., Equations of Motion for Free-Flight Systems of Rotating-Translating Bodies, Sandia Laboratories, Albuquerque, New Mexico, SAND76-0266, September 1976.

5. J. L. Meriam, Statics and Dynamics, New York, London: John Wiley and Sons, Incorporated, 1966.

6. G. G. Wilson, Quaternion Representation of Rigid-Body Finite Rotations, Sandia Laboratories, Albuquerque, New Mexico, SC-TM-72 0230, April 1.972.

7. A. E. Hodapp, Jr., Equations of Motion for Constant Mass Entry Vehicles With Time Varying Center of Mass Position, Sandia Laboratories, Albuquerque, New Mexico, November 1970. 


\section{DISTRIBUTION:}

Aerospace Corporation 2350 El Segundo Blvd. Los Angeles, CA 90009

Attn: D. H. Platus

ARO, Inc. (2)

vonKarman Gas Dynamics Facility

Arnold Air Force Station, TN 37389

Attn: J. C. Uselton

C. J. Welsh

AVCO Corporation

Missile Systems Division

201 Lowell St.

Wilmington, MA 01887

Attn: I. Sacks

Ballistic Research Laboratories (3)

Aberdeen Proving Ground, MD 21005

Attn: $C, H$, Murphy, DRDAR-BLL-FT

R. F. Lieske, DRDAR-BLL-FT

V. Oskay, DRDAR-BLL-FT

General Electric Company

Reentry Systems Department

3198 Ches tnut St.

Philadelphia, PA 19101

Attn: J. J. Pettus

General Electric Company

Armament Systems Department

Lakeside Ave.

Burlington, VT 05401

Attn: R. H. Whyte

Kaman Sciences Corporation

1700 Garden of the Gods Road

Colorado Springs, CO 80907

Attn: F. Barberra

Lockheed Missiles and Space Cumpany

P. O. Böx 504

Sunnyvale, CA 94088

Attn: L. E. Ericsson

Los Alamos Scientific Laboratory, (3)

P. O. Box 1663

Los Alamos, NM 87544

Attn: R. N. Thorn, DIR-O(Mail Stop 100)

E. H. Eyster, WX-DO(Mail Stop 686)

H. P. Deinken, WPC-1(Mail Stop 634)

US ARRADCOM Headquarters (3)

Dover, NJ 07801

Attn: C. J. Spinelli, DRDAR-LCN-DP

A. A. Loeb, DRDAR-LCA-FB

D. H. Mertz, DRDAR-LCA-FB
The John Hopkins University

Applied Physics Laboratory

John Hopkins Road

Laurel, MD 20810

Attn: L. S. Glover

University of California (2)

Lawrence Livermore Laboratory

P. O. Box 808

Livermore, CA 94550

Attn: W. F. Scanlin, Jr., L-24

W. K. Haslam, L-122

Naval Surface Weapons Center (2)

White Oak Laboratory

Silver Spring, MD 20910

Attn: S. Hastings, Code 312

F. J. Regan, Code 312

Naval Surface Weapons Center

Dahlgren Laboratory

Dahlgren, VA 22448

Attn: T. Clare, Code T1-3

Commander

Edgewood Arsenal

Aberdeen Proving Ground, MD 21010

Attn: M. C. Miller, DRDAR/ACW

1000 G. A. Fowler

1300 D. B. Shuster

1310 A. A. Lieber

1320 M. M. Newsom

1330 R. C. Maydew.

1331 H. R. Vaughn (20)

1331 A. E. Hodapp (10)

1332 C. W. Peterson

1333 S. McAlees, Jr.

1334 D. D. McBride

1335 W. R. Barton

1350 R. F. Flem

8010 A. N. Blackwell

8100 L. Gutierrez

8120 W. E. Alzheimer

8122 G. A. Benedetti

8150 D. E. Gregson

8152 G. N. Beeler

8152 R. N. Everett

8153 D. J. Bohrer

8354 B. R. Sanders

8360 J. F. Barham

8366 J. D. Gilson

8410 R. Baroody

8266 E. A. Aas

3141 C. A. Pepmueller (Actg) (5)

3151

W. L. Garner (3) For DOE/TIC (Unlimited Release)

DOE/TIC (25)

(R. F. Campboll, 3172-3) 